\title{
DOE FIELD VERIFICATION PROGRAM FOR SMALL WIND TURBINES
}

Site Location: Spanish Fork, Utah

Final Report

Dean A. Davis

A. Craig Hansen

Windward Engineering, LLC

4661 Holly Lane

Salt Lake City, UT 84117

September 30, 2003

\section{PREPARED FOR THE UNITED STATES \\ DEPARTMENT OF ENERGY \\ Under Cooperative Agreement \\ No. DE-FC36-99GO10460}




\section{Table of Contents}

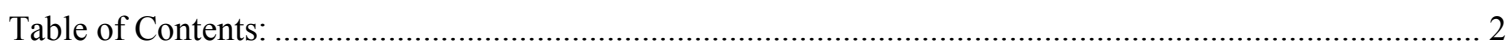

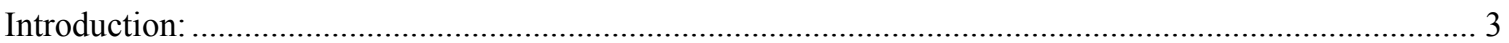

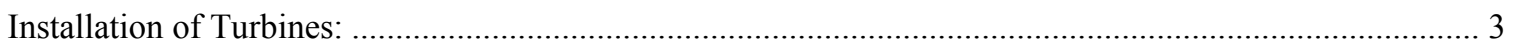

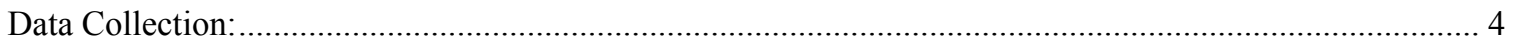

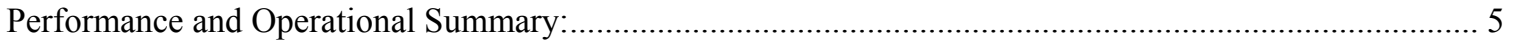

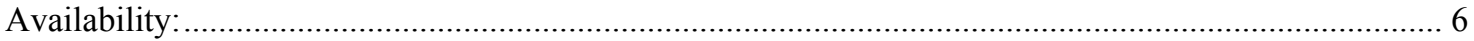

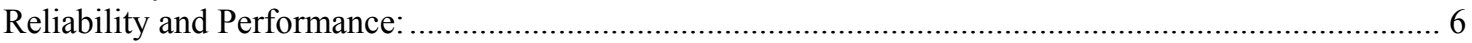

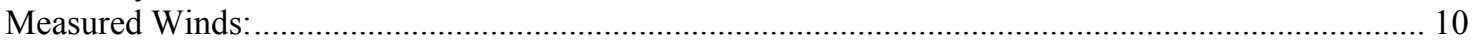

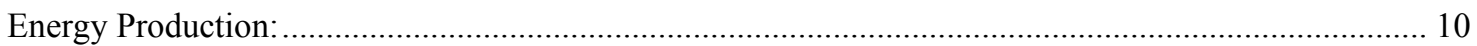

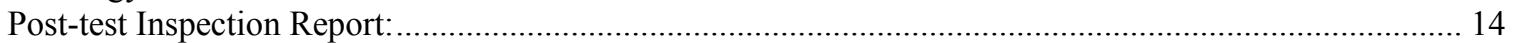

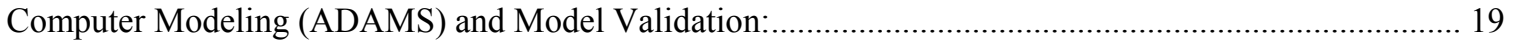

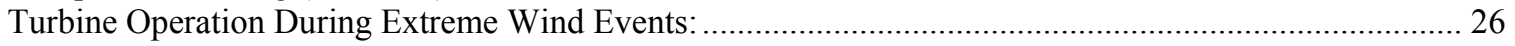

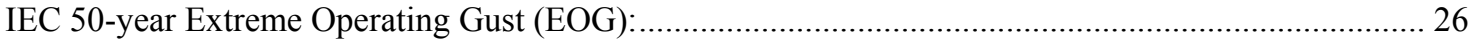

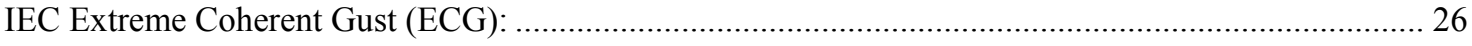

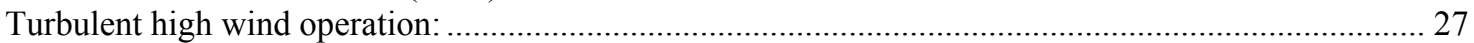

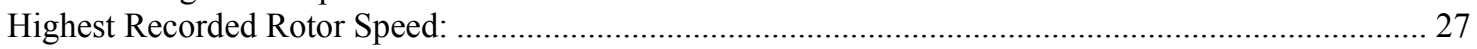

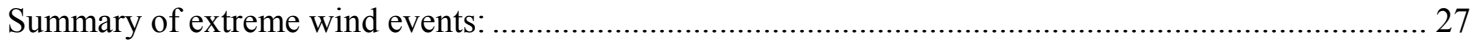

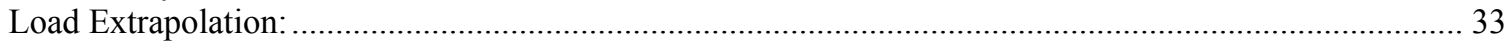

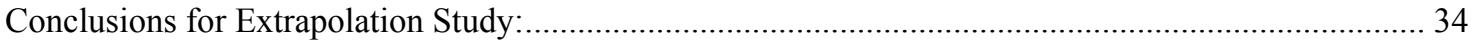

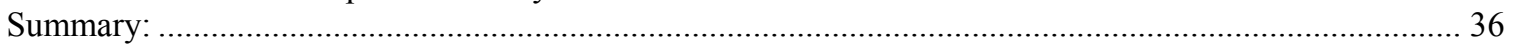

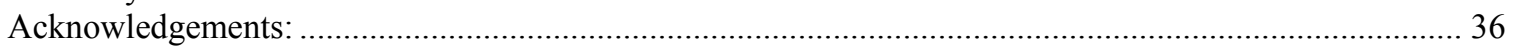

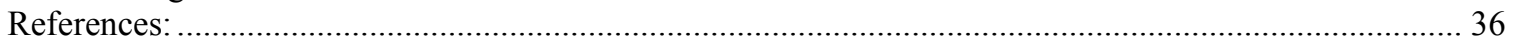




\section{Introduction:}

In 1999 Windward Engineering (Windward) was awarded a Cooperative Agreement under the Field Verification Program with the Department of Energy (DOE) to install two Whisper H40 wind turbines, one at the NREL National Wind Technology Center (NWTC) and one at a test site near Spanish Fork, Utah. After installation, the turbine at the NWTC was to be operated, maintained, and monitored by NREL while the turbine in Spanish Fork was to be administered by Windward.

Under this award DOE and Windward defined the primary objectives of the project as follows:

1) Determine and demonstrate the reliability and energy production of a furling wind turbine at a site where furling will be a very frequent event and extreme gusts can be expected during the duration of the tests.

2) Make engineering measurements and conduct limited computer modeling of the furling behavior to improve the industry understanding of the mechanics and nature of furling.

We believe the project has achieved these objectives. The turbine has operated for approximately three and a half years. We have collected detailed engineering data approximately 75 percent of that time. Some of these data were used in an ADAMS model validation that highlighted the accuracies and inaccuracies of the computer modeling for a passively furling wind turbine. We also presented three papers at the American Wind Energy Association (AWEA) Windpower conferences in 2001, 2002, and 2003. These papers addressed the following three topics: a) general overview of the project [1], b) furling operation during extreme wind events [2], and c) extrapolation of extreme (design) loads [3]. We believe these papers have given new insight into the mechanics and nature of furling and have set the stage for future research.

In this final report we will highlight some of the more interesting aspects of the project as well as summarize the data for the entire project. We will also present information on the installation of the turbines as well as the findings from the post-test inspection of the turbine.

\section{Installation of Turbines:}

Both the Spanish Fork (Figure 1) and NWTC (Figure 2) turbines were installed during the winter of 1999-2000. For the Spanish Fork turbine concrete foundations were poured for both the tower base and a small winch pad. The guy attachment anchors used Manta Ray earth anchors that were pounded in with a jackhammer then pulled back, rotating and setting them in the ground as recommended by the manufacturer. All electrical wiring was routed in underground conduit back to the instrumentation trailer. An extensive lightning protection system was installed both underground and in the instrumentation trailer since we have had lightning damage in earlier projects at the site.

We summarized the installed cost for the Spanish Fork installation (excluding equipment rentals, site specific costs such as our lightning protection, and our labor costs) in Table 1. These numbers might be a useful guideline for anyone interested in installing this turbine. At the bottom of the table it shows that $54 \%$ of the installed cost is associated with the inverter and its disconnect. This highlights the fact that although this is a relatively inexpensive turbine if one desires to have it grid connected, the inverter-associated costs will more than double the total cost. It should also be noted that a

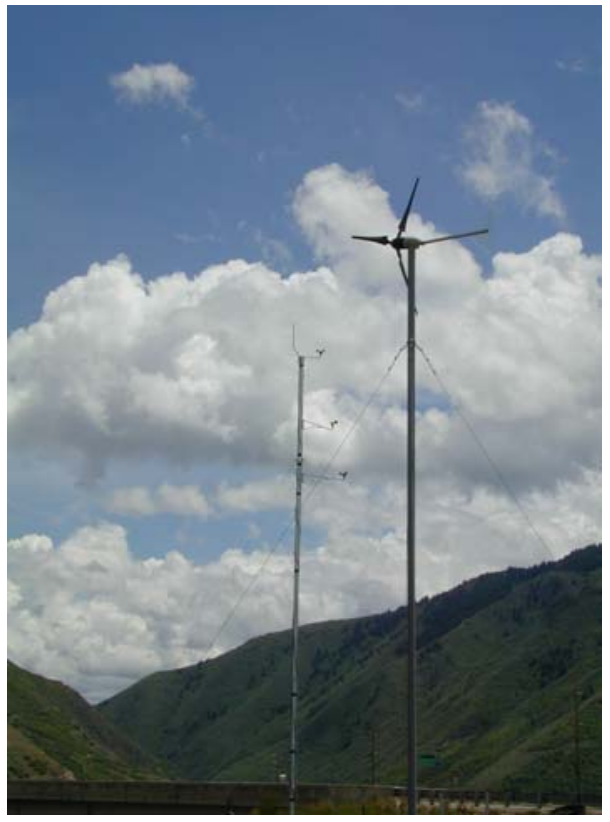

Figure 1. Whisper H40 installed at the Spanish Fork test site. 
neat and professional installation would require underground conduit and some electrical boxes. Although these additions will not dramatically increase the overall purchase cost they will add to the required labor.

The turbine installed at the NWTC used an existing concrete pad (site 1.3) for the tower base. We again installed the Manta Ray earth anchors for the guy anchor attachment. An instrumentation trailer and underground conduit were already located at the site. A local electrical contractor was used to help install the electrical components such as the inverter and batteries.

\section{Data Collection:}

Data has been monitored via two independent monitoring systems. The first is a NRG 9300 data logger which logged statistics of each channel every 10minutes. This system was the primary system used for overall turbine performance and operation. It monitored the following 8 channels.

1. Turbine Power

2. Rotor Speed

3. Wind Speed at 34,

4. Wind Speed at 27'

5. Wind Direction (at hub height, $30.5^{\prime}$ )

6. Ambient Temperature

7. Barometric Pressure

8. Turbine Availability

Energy production was measured at two locations, as "wild" AC coming into the instrumentation trailer and as 60 cycle $120 \mathrm{~V}-\mathrm{AC}$ delivered to the grid. Energy totals were monitored monthly.

Although the statistical 10-minute values were necessary for long term monitoring, we also desired some short term monitoring at higher sample rates to capture the details of short-term events. For this purpose we used a Labview data acquisition system. The Labview system uses signal conditioning hardware connected to a personal computer. The Labview software was programmed in order to get a user-friendly interface, informative front panel display as well as for preliminary processing of the data. Figure 3 shows the front panel used on the Whisper DAQ system. This system originally monitored the following 7 channels at a sample rate of $5 \mathrm{~Hz}$.
1. Turbine Power
2. Rotor Speed
3. Wind Speed at 34'
4. Wind Speed at 27
5. Wind Direction (at hub height, $30.5^{\prime}$ )
6. Furl Angle
7. Yaw Angle

Table 1. Cost breakdown for installation of the Whisper H40 at the Spanish Fork Test Site. All costs are equipment expenses without any labor costs.

\begin{tabular}{|lrr|}
\hline Component & $\begin{array}{r}\text { Cost (1999 } \\
\text { dollars) }\end{array}$ \\
\hline \hline Turbine (Whisper H40) & $\$$ & 1,526 \\
tower kit & $\$$ & 557 \\
tower pipe & $\$$ & 305 \\
foundation engineering & $\$$ & 275 \\
foundation (concrete, rebar) & $\$$ & 94 \\
anchors & $\$$ & 130 \\
wire & $\$$ & 61 \\
batteries & $\$$ & 288 \\
battery box & $\$$ & 130 \\
inverter (Trace SW4024) & $\$$ & 3,274 \\
inverter disconnect (DC 250) & $\$$ & 618 \\
Total & & \\
Inverter percentage of total & $\$$ & 7,258 \\
& & $54 \%$ \\
\hline
\end{tabular}

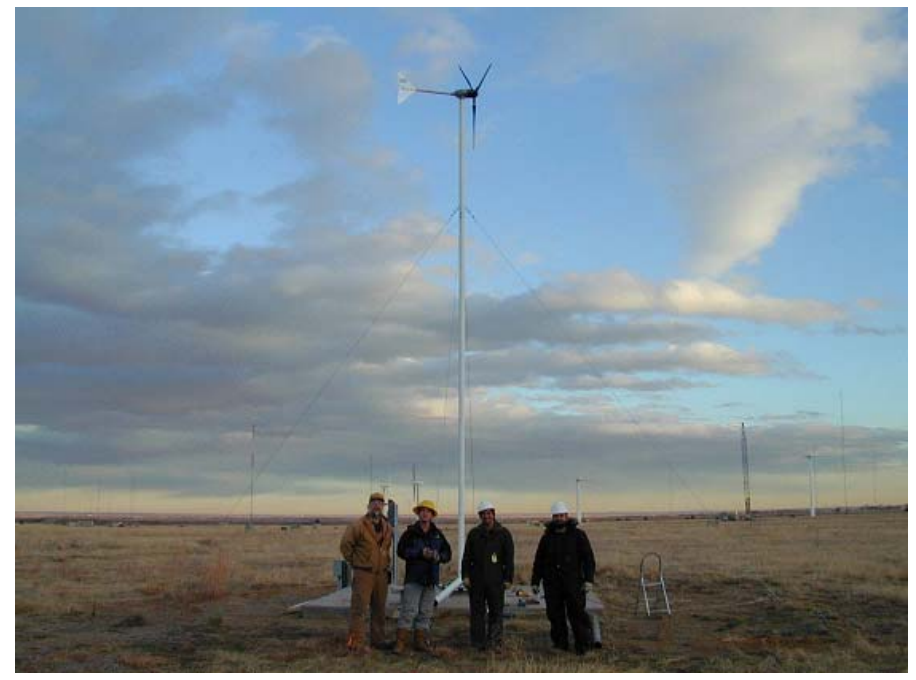

Figure 2. Turbine installed at National Wind Technology Center near Boulder Colorado. 


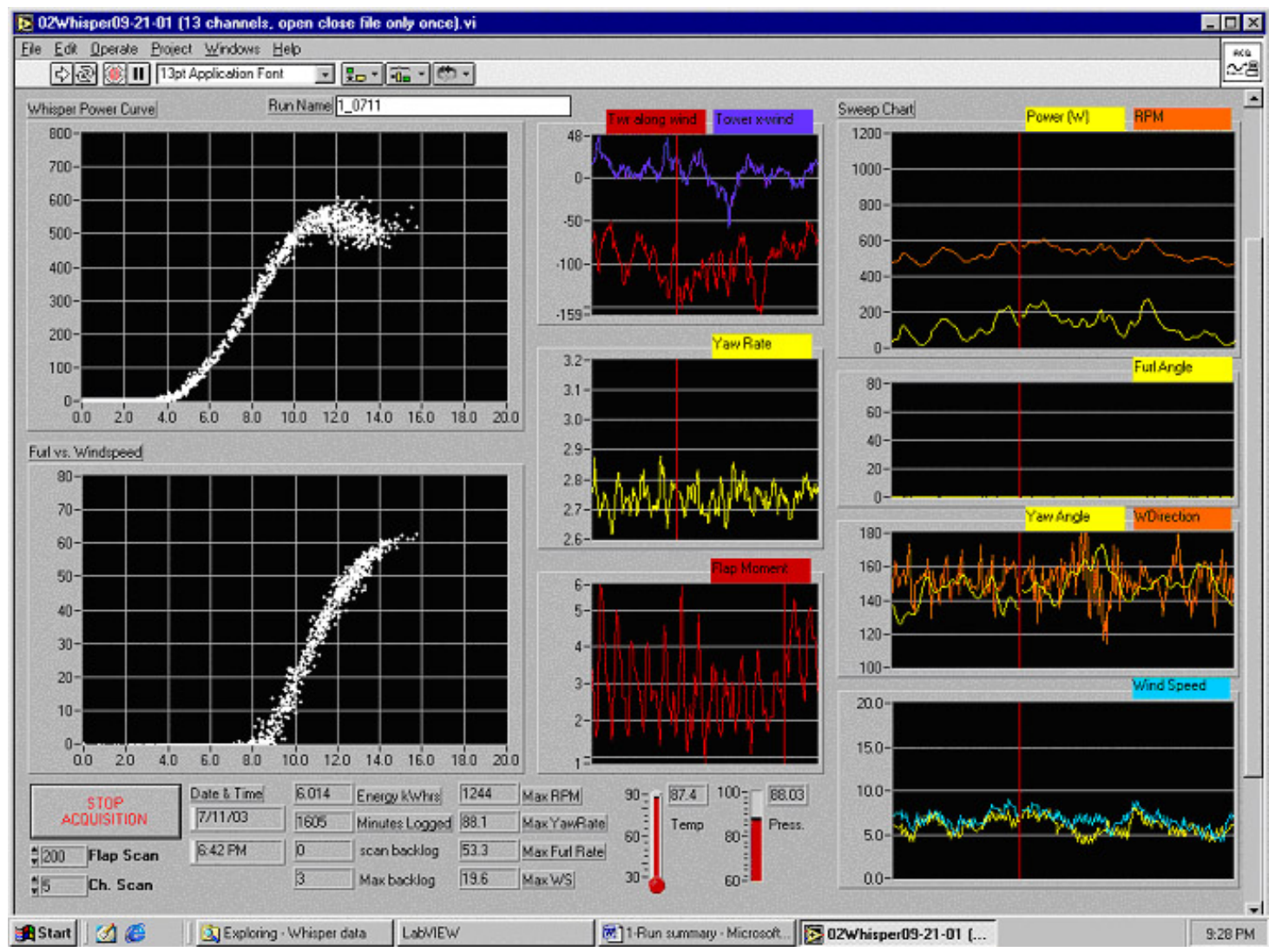

Figure 3. Labview front panel showing details of the collected data set.

During the latter part of 2001 additional instrumentation was added in order to monitor some turbine loads. The new instrumentation included a yaw rate sensor, two tower bending gages above the tower guys (see Figure 4), and one set of blade flap bending moment gages. Although the original sample rate of $5 \mathrm{~Hz}$ was sufficient for monitoring most channels it was too slow for getting good measurements on the blade root flap bending moment gage. This is because the rotor can rotate faster than $1,500 \mathrm{rpm}$ (or 25 $\mathrm{rev} / \mathrm{sec}$ ) resulting in only one sample every five revolutions. As a result we changed the data sample rate on the blade flap bending moment channel to $200 \mathrm{~Hz}$. This resulted in eight samples/revolution even at the very highest rotor speeds but also resulted in large data files. For this reason we typically collected data only while the winds were blowing (overnight).

The data collected on the Labview system were used for monitoring of extreme loads, extrapolation of loads, as well as for validation of the ADAMS computer model.

\section{Performance and Operational Summary:}

The 10-minute average data were continuously monitored and logged. These data were processed and summarized in each of the fifteen quarterly reports. In this section we have condensed the entire data set into a few figures showing an overall summary.

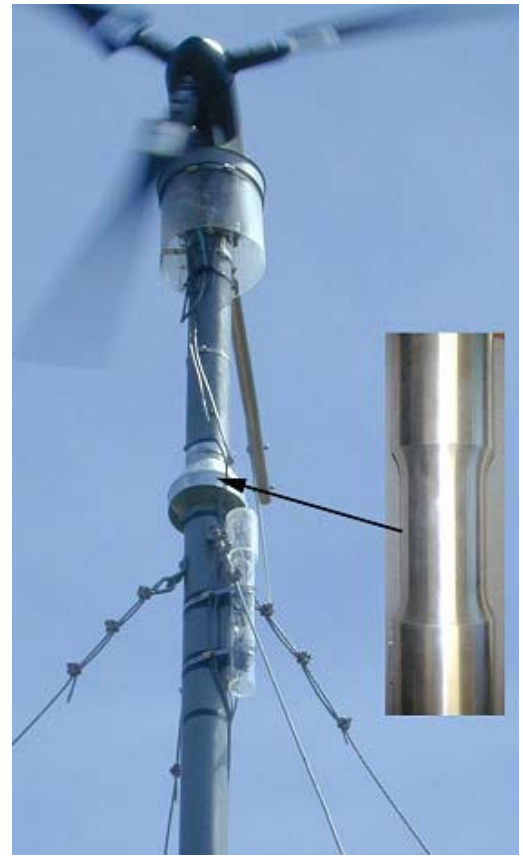

Figure 4. The tower bending transducer was custom-built to allow for higher strain, resulting in a measurable signal even during lower wind speeds. 


\section{Availability:}

Figure 5 shows a plot of the availability of the entire wind turbine and DAQ system over the entire project ( $\sim 3.5$ years). From this plot we find that the overall availability was approximately $74 \%$, with much of the downtime coming in the later part of the project. When we categorize the reasons for the downtime we find that a majority of the downtime was associated with the instrumentation: installation, debugging and calibration, or data logger faults. When looking at the longer period shutdowns we find the causes shown below in Table 2. The availability of the Whisper turbine, EZ wire controller, batteries, and inverter was $98 \%$.

Table 2. Reasons the turbine was shutdown for extended periods of time. The total of these shutdowns represent $95 \%$ of all of the system unavailable time (338 hours).

\begin{tabular}{lrr}
\hline & \multicolumn{2}{c}{ Percent of the Total } \\
Cause of downtime & Downtime & \\
\hline Collecting of turbine properties & $5 \%$ \\
\hline Instrumentation related (installation, debugging, or calibration) & $42 \%$ \\
\hline Turbine vandalism & $8 \%$ \\
\hline EZ wire diode failure & $7 \%$ \\
\hline NRG 9300 faults & $23 \%$ \\
\hline Post-test Inspection & $8 \%$ \\
\hline
\end{tabular}

\section{Reliability and Performance:}

The reliability of the turbine, batteries, and inverter were all very good. There were only two notable turbine faults: a blown diode in the EZ wire controller and a sticking furl bushing. The batteries and inverter performed without fault. The turbine was out of operation for 25 days while we debugged the blown diode problem and waited for a replacement part. Almost all of this down time was associated with a delayed response from Southwest Windpower on shipping us the new part. The sticking furl bushing resulted in a poorer than usual power curve but the turbine continued to operate until the replacement part was received. The actual downtime associated with replacement of the bushing was insignificant, approximately 2 hours.

Although we were pleased with the reliability of the turbine and inverter we found the power performance less than expected. Figure 6 plots the power curves measured during each quarter of the project. We can see that the power curve does not vary significantly at the lower wind speeds but does have some variability near rated power. Much of the variability in the power curve at the lower wind speed is likely due to the changes in air density while the larger differences found near rated power are more likely a function of the limited and variable amount of time the turbine was operating in the high winds during each quarter. When we analyze all of the quarters we find that rated power is between approximately 500 and 600 watts with the average near 550 watts. This is approximately $60 \%$ of the expected 900 watts ${ }^{1}$. One possible reason for lower power output is the reduction in air density due to high elevation. The elevation of the Spanish Fork test site is 4,800ft $(1,463 \mathrm{~m})$, hence the air density averages $17 \%$ less than sea-level. The IEC standard for normalizing a power curve to ISO standard atmosphere (sea-level) uses either 1) the density ratio as a multiplier on the power output for a stall regulated, constant pitch, constant speed wind turbine or 2) a shift in the wind speed by the cube root of the density ratio for an actively controlled wind turbine. Although a passively furling wind turbine does not fall within the guidelines of the standard we believe that the true density correction would fall between the two options in the standard and more specifically closer to the shifting of the wind used for an actively controlled wind turbine (i.e. not reducing the rated power from 900 watts but instead shifting it to occur at a higher wind speed).

\footnotetext{
${ }^{1}$ The turbine is marketed as having a rated output of 900 watts.
} 
System Availability - World Power Technologies - Whisper H40

(Spanish Fork, UT Test Site)

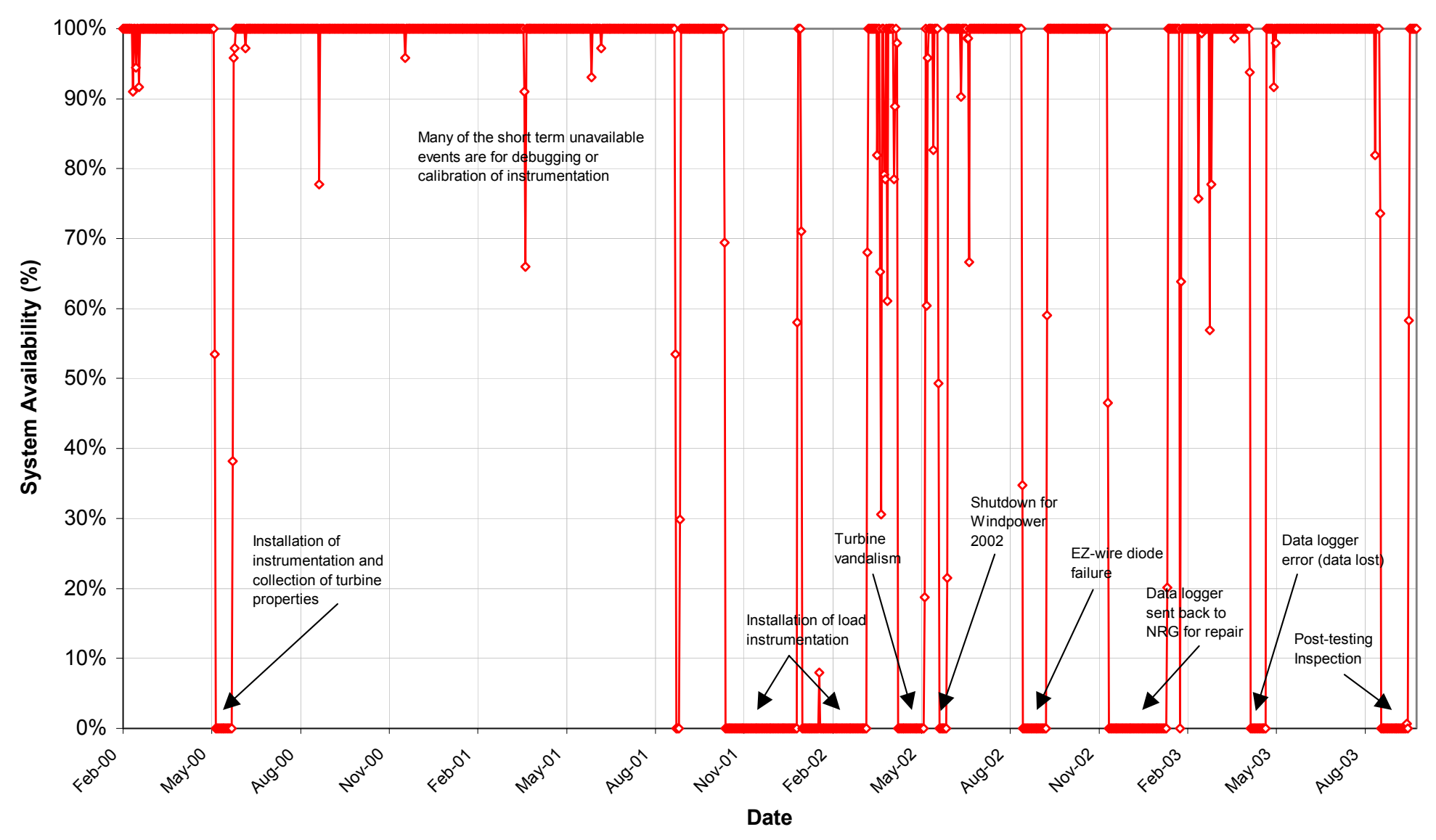

Figure 5. System availability for the entire test period. 


\section{World Power Technologies - Whisper H40 Power Curve \\ (Spanish Fork, UT Test Site) \\ 26 February 2003 - 31 September 2003}

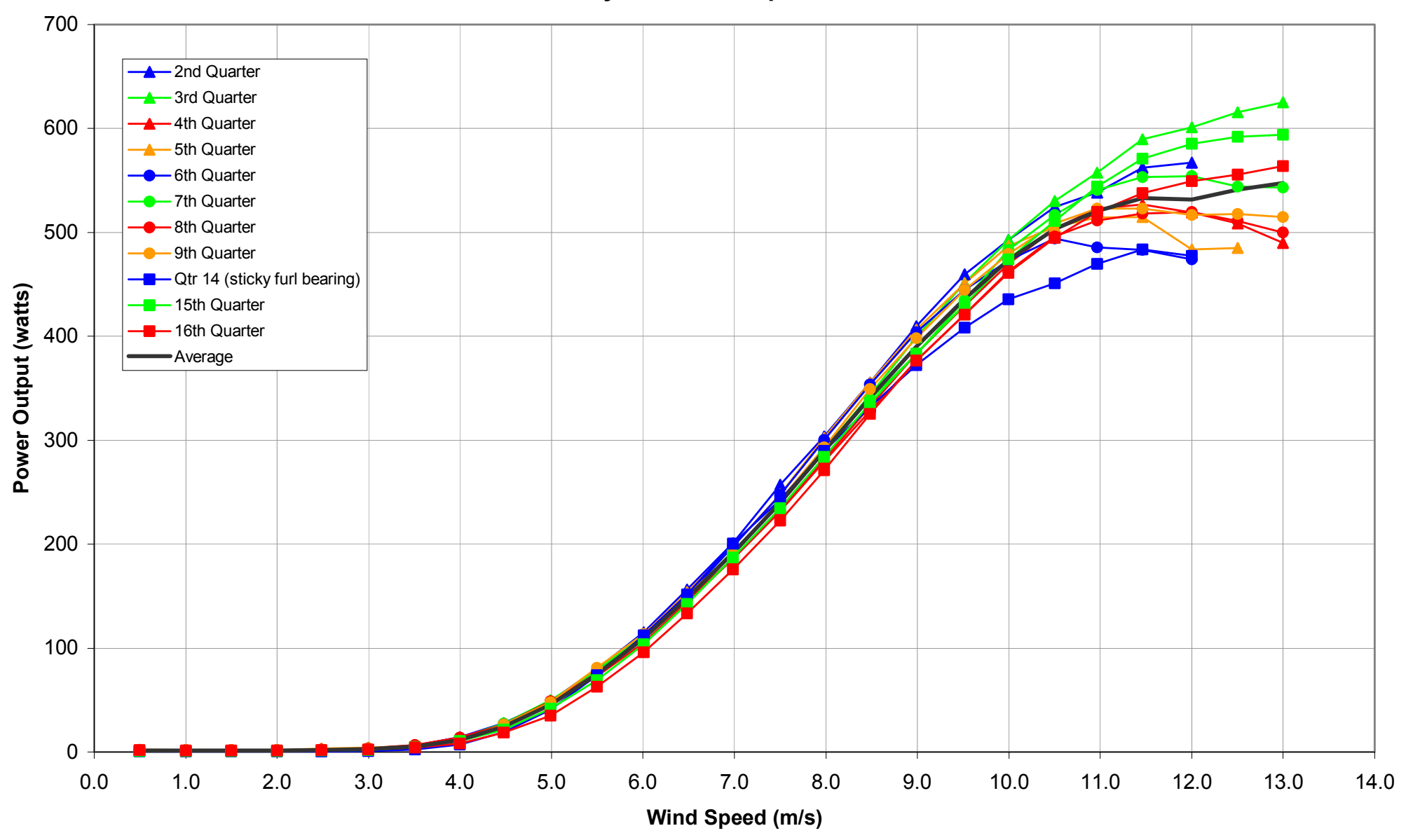

Figure 6 Power curve for Whisper H40 wind turbine during all project quarters with high system availability. Power measured at instrumentation trailer before EZ-wire controller (rectifier), batteries, and inverter. These curves are not density corrected. 
We also suspected that the poor power performance was not specific to our particular turbine or test site. This was confirmed by a power curve comparison between measurements made in Spanish Fork and those made on the sister turbine that was tested at the NWTC (see Figure 7).

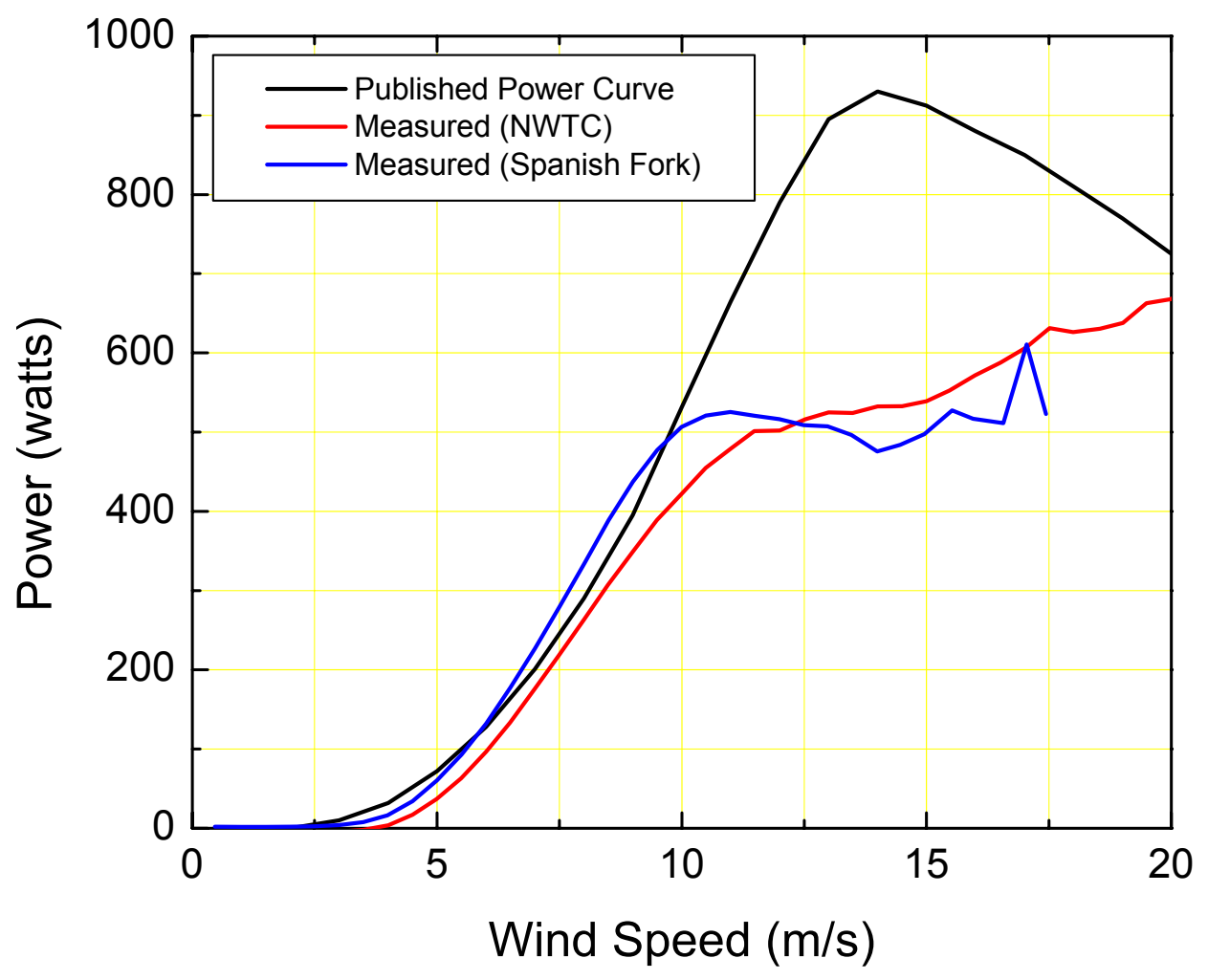

Figure 7. Measured and published power curves for the Whisper H40. Both measured power curves were density corrected to standard sea-level. The NWTC power curve was measured at the DC bus between the EZ-wire and the batteries. The Spanish Fork power curve was measured before the EZwire (and it's associated losses) and is consistent with higher power measurements when compared to the NWTC power curve. The published data was found in a dealer catalog.

We have had trouble free operation of the Trace SW-4024 inverter and the four Interstate (golf cart) batteries used to deliver the power to the local utility grid. However, we are measuring a substantial power loss within these electrical components. During Whisper testing we measured the power as it entered the instrumentation trailer where it is still "wild AC" (variable frequency/variable voltage AC). We also monitored total energy production at that location using a power integrator. The power then enters the EZwire controller where it is rectified and sent to our small (four-battery, $24 \mathrm{~V}$ ) battery bank. Once the inverter detects a rise in the battery bank voltage it draws energy from the batteries and delivers it to the grid. A utility power/energy meter monitors this power as it is fed into the grid. By comparing the energy on the power integrator to the utility meter we have been able to monitor any losses associated with the EZwire controller, the battery bank, and the inverter. This conversion efficiency was calculated quarterly, showing little variability, and shows an overall efficiency of $77 \%$ for the entire three and a half year test period. 


\section{Measured Winds:}

The Whisper testing used a meteorological tower (met. tower) situated $35.5 \mathrm{ft}$ ( $\sim 5$ rotor diameters) upwind of the wind turbine. The met. tower was outfitted with two anemometers, one at hub height plus one rotor radius (34') and one at hub height minus one rotor radius (27'). Having two anemometers allows an estimate of the vertical wind shear across the rotor but more importantly we had redundancy in the instrumentation to help detect any erroneous data values. All wind speeds shown in this report were the average wind speed of the two anemometers unless one anemometer was shown to be faulty. Also fitted on the met. tower were barometric pressure, ambient temperature, and hub height wind direction sensors.

The state of Utah monitored winds at the test site for over four years before 1995 and we have been testing wind turbines at the test site since 1995. We therefore have a good idea of the wind resource and there were few surprises in the measured wind data. The only notable surprises were 1) we saw severe wind gusts more frequently than we had expected and 2) the dramatic reduction in the occurrence of high wind speeds due to the high vertical wind shear and the short $(30.5 \mathrm{ft})$ test tower. Figures 8 and 9 show the overall measured wind distribution and how the wind is distributed about the time of day.

Although extreme wind gusts are not ideal for a production wind site, these wind events, if captured by the DAQ system are very interesting and informative for evaluation of how the turbine protects itself. They also shed light on what extreme wind events are most likely to cause the highest structural loading for the turbine. A later section of this report details the turbine operation during extreme wind events.

The high vertical shear combined with the very short $30.5^{\prime}$ tower used during this project, resulted in a lower average wind speeds and made it more difficult to collect data at the higher wind speeds. When comparing the amount of time above $17 \mathrm{~m} / \mathrm{s}$ the Whisper testing showed just over 3 hours per year while the data collected at 95' shows over 200 hours per year'. Although using a short tower had little influence on the project, using an $80 \mathrm{ft}$ tower would have been more representative to what a typical customer might use and would have allowed us to better define the high wind end of the power curve.

\section{Energy Production:}

The Whisper produced a total of $4468 \mathrm{kWh}$ during the project and delivered $77 \%$ ( $3425 \mathrm{kWh}$ ) to the local power grid. Figure 10 shows the running total of the energy produced during the project. The longer downtimes can be identified on the plot by the flat periods where zero energy was produced. These longer downtimes were labeled with the reason for the turbine's shutdown. If we exclude the downtimes we find that the turbine produced, on average, $4.6 \mathrm{kWh}$ per day and delivered $3.5 \mathrm{kWh}$ of this energy to the grid.

\footnotetext{
${ }^{2}$ The 95' data was collected over a four-year period by the state of Utah and is published in the Utah Wind Survey Report [5]. The state of Utah anemometer tower is still located on-site and is approximately 175 ' downwind from the Whisper anemometer tower. Although this report showed a large vertical shear (0.294 power law) at the Spanish Fork site we did not recognize the extent in which this shear would reduce the amount of time at higher wind speeds.
} 
Wind Speed Distribution Curve - Spanish Fork Test Site 26 February 2003 - 31 September 2003

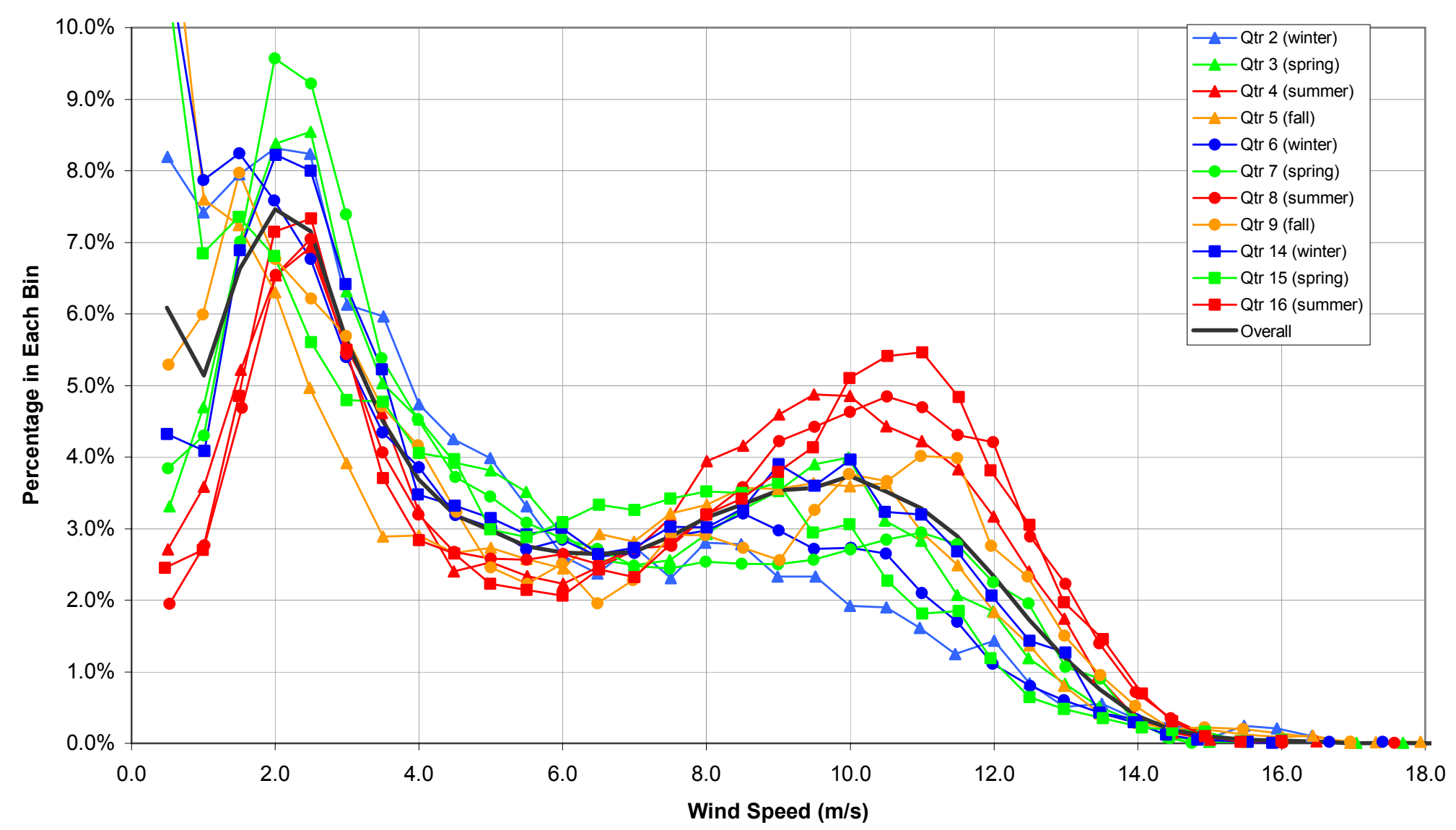

Figure 8. Wind speed distribution measured during Whisper H40 testing. Note that some quarters (where data was not collected) are not included on this plot. Bin width is $0.5 \mathrm{~m} / \mathrm{s}$. 
Average Wind Speed vs. Time of Day - Spanish Fork, UT Test Site 26 February 2003 - 31 September 2003

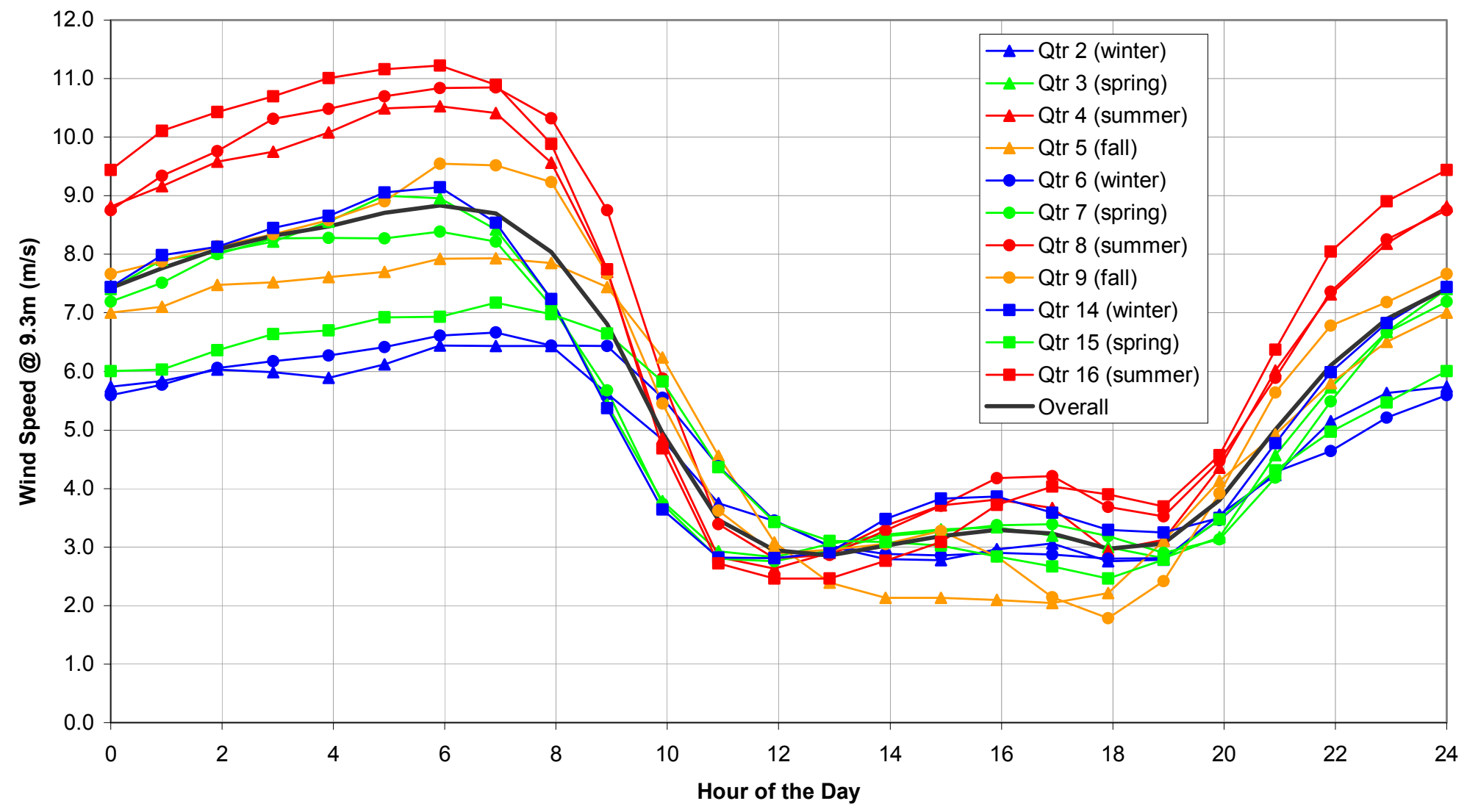

Figure 9. Average wind speed vs. time of day for the measured winds in Spanish Fork. Note that some quarters (where data was not collected) are not included on this plot. 


\section{Energy Production (running total) - World Power Technologies - Whisper H40}

(Spanish Fork, UT Test Site)

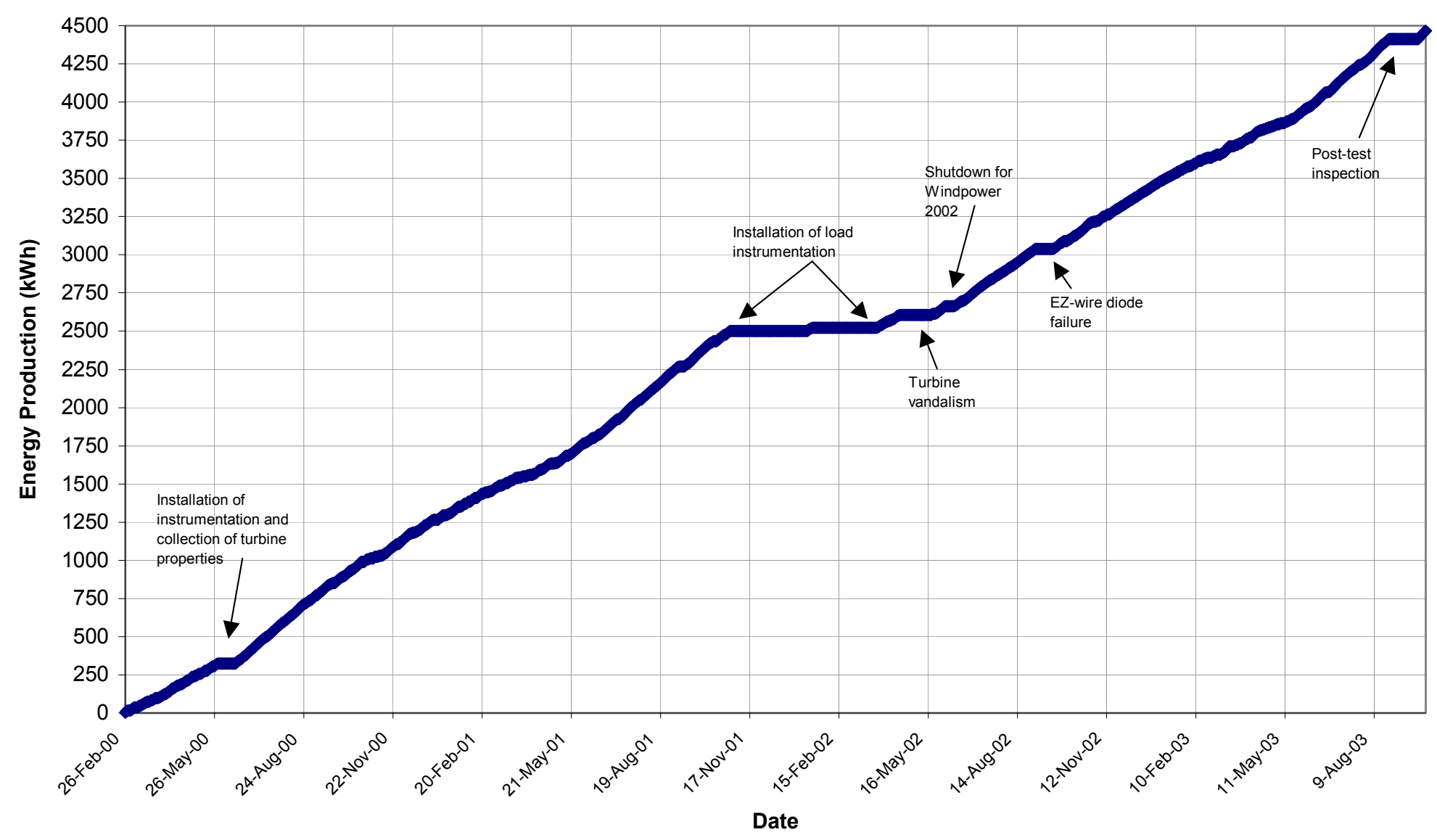

Figure 10. Running total of energy production with longer unavailable times labeled. 


\section{Post-test Inspection Report:}

Late in August of 2003 the turbine was removed from the tower and taken to the NWTC for a post-test inspection. At the NWTC Jim Adams was in charge of inspecting the turbine and evaluation of the components. This inspection showed only minor wear problems and overall showed the turbine to be in good condition. Photos 1 through 5 show some wear between the magnet can and the housing and between the two main frame housing pieces. Photo 6 shows wear on insulation of the power wires. Continued wear would have eventually caused the generator to short against the turbine body. Photo 7 and 8 show the yaw bearings and the rotor bearings. Nether set of bearings sounded rough or gave any indication of failure but the yaw bearings appeared to have failing seals and one of the rotor bearings was rusting due to trapped moisture.

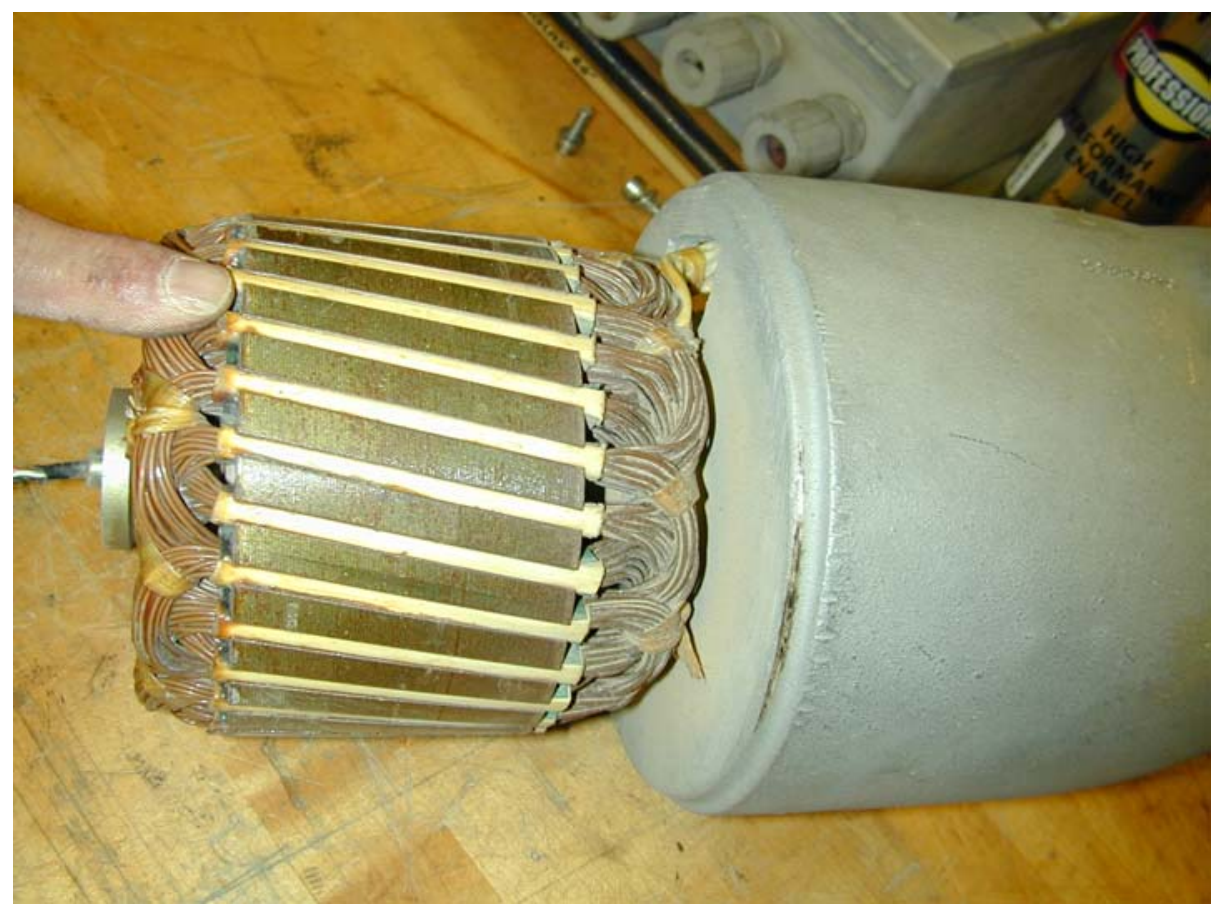

Photo 1. Some wear was seen where the magnet can was rubbing the main turbine housing. 


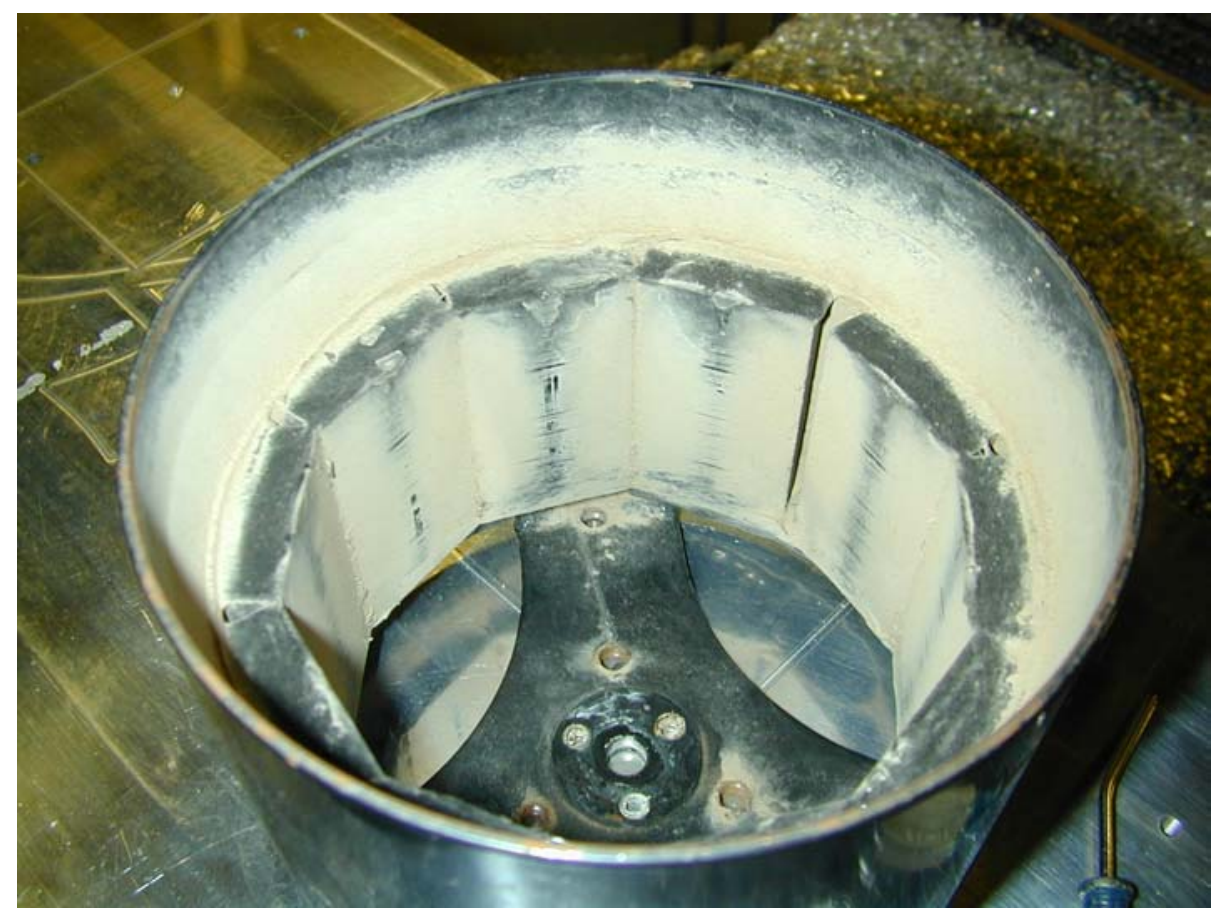

Photo 2. Minor wear can be seen on the magnets where they were in contact with the generator laminates.

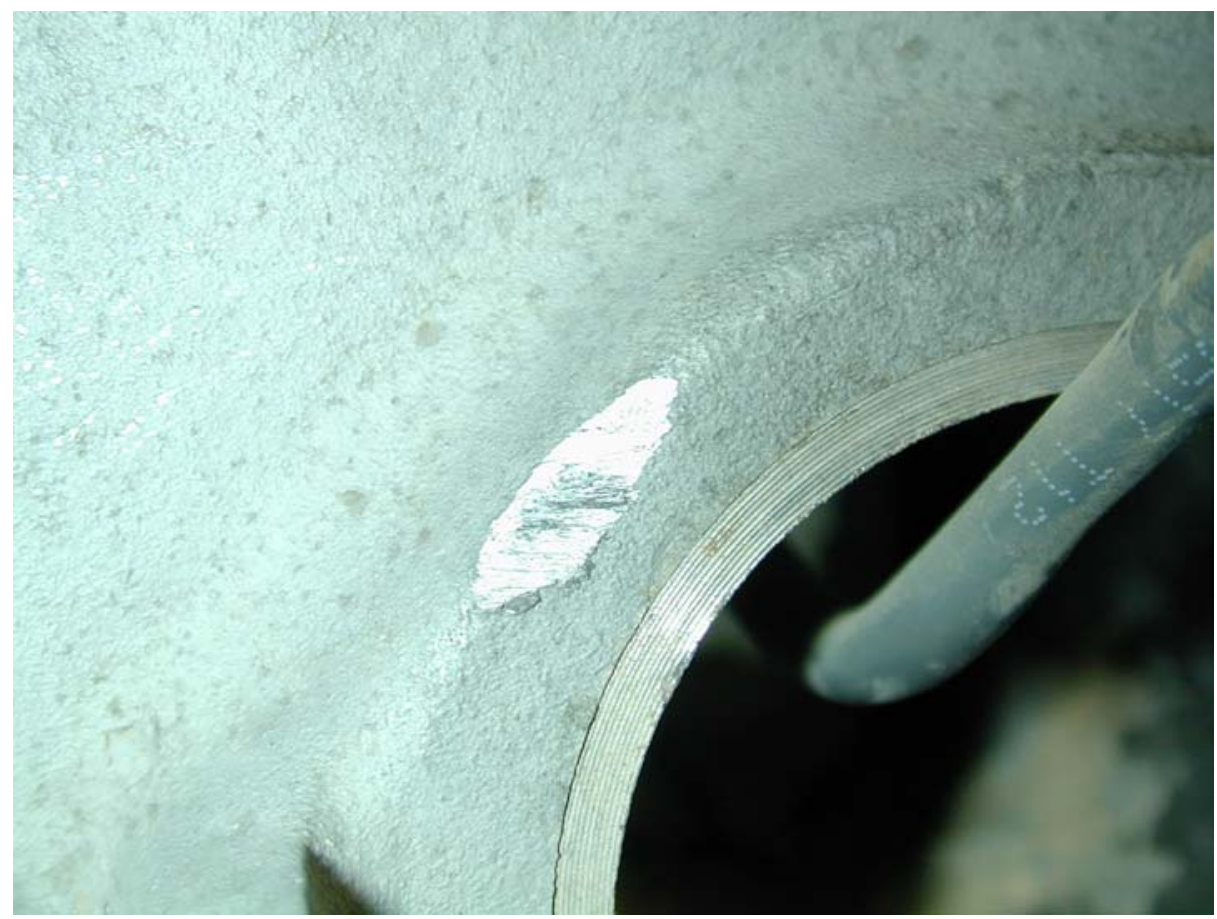

Photo 3. There were a few locations where the upper body (furling generator portion) was rubbing the lower turbine body. Here we can see some rubbing on the generator portion. 


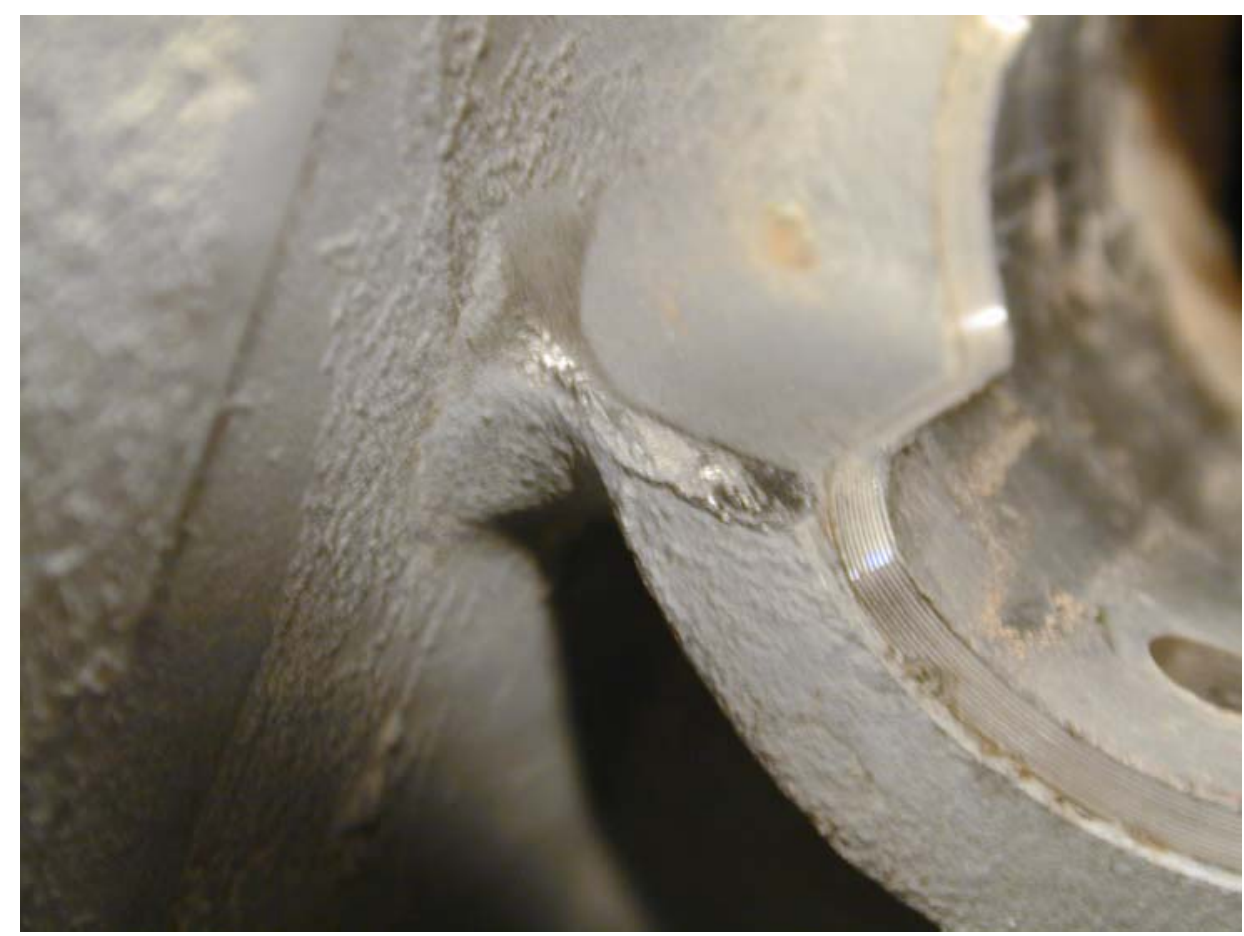

Photo 4. Another location where the two turbine body halves were rubbing, this on the generator portion.

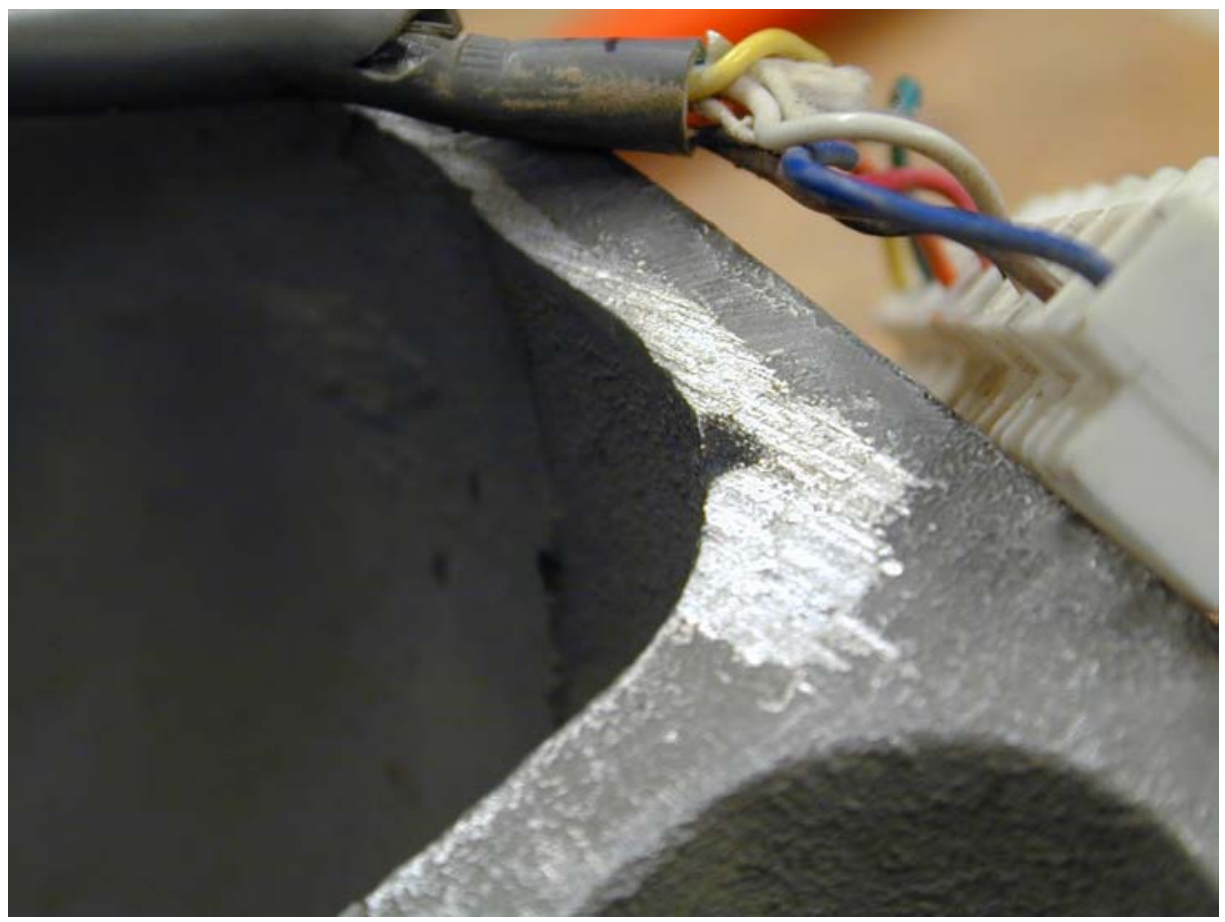

Photo 5. One more location where the two turbine body halves were rubbing, again on the generator portion. 


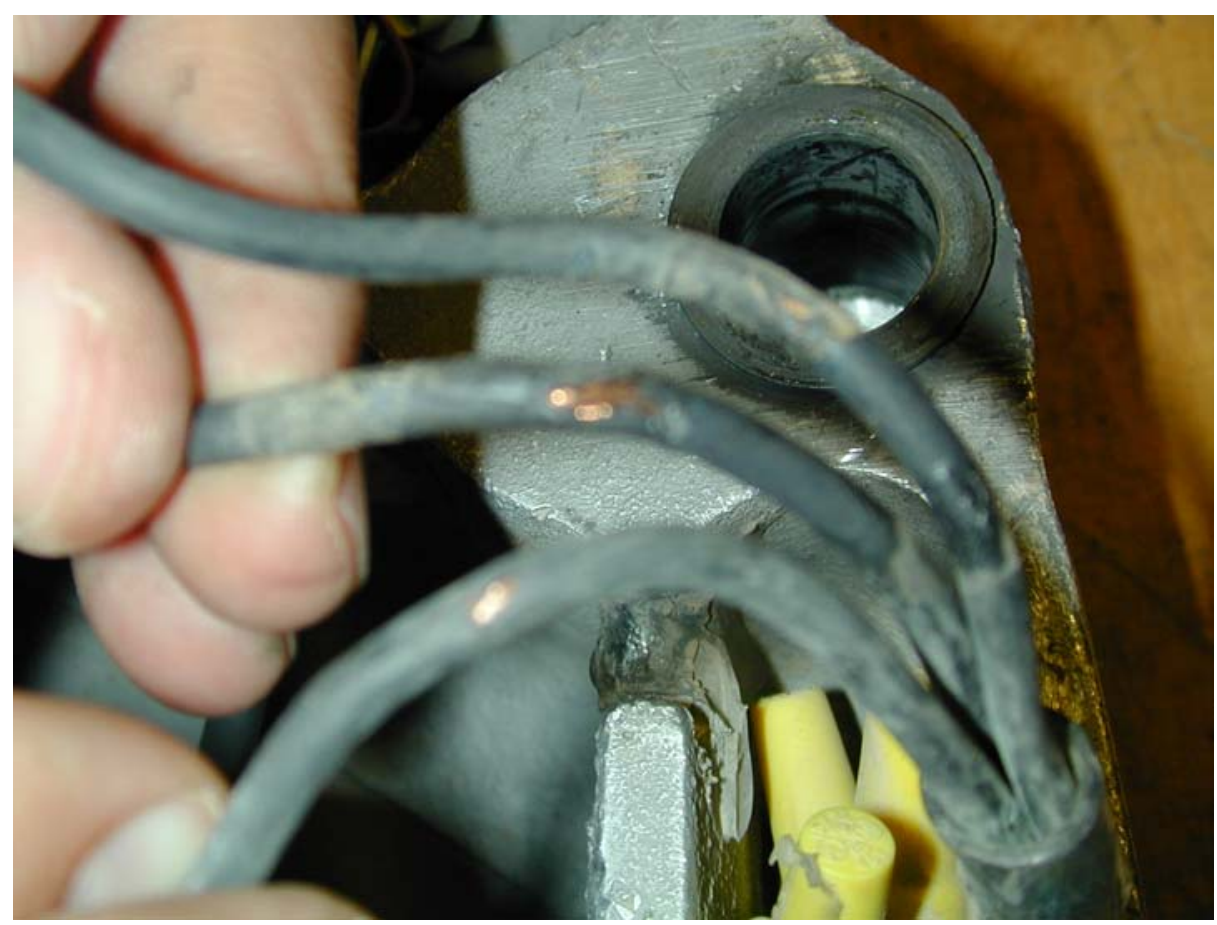

Photo 6. The power wires lie loose (by design) inside the turbine body. When the generator portion of the turbine body rotates during furling the wires are required to rotate into a narrow gap. Although the gap should not pinch the wires it can cause abrasion. This photo shows the abrasion seen on the power wires and shows that a more abrasion resistant wire insulation is required to avoid eventually shorting out the turbine.

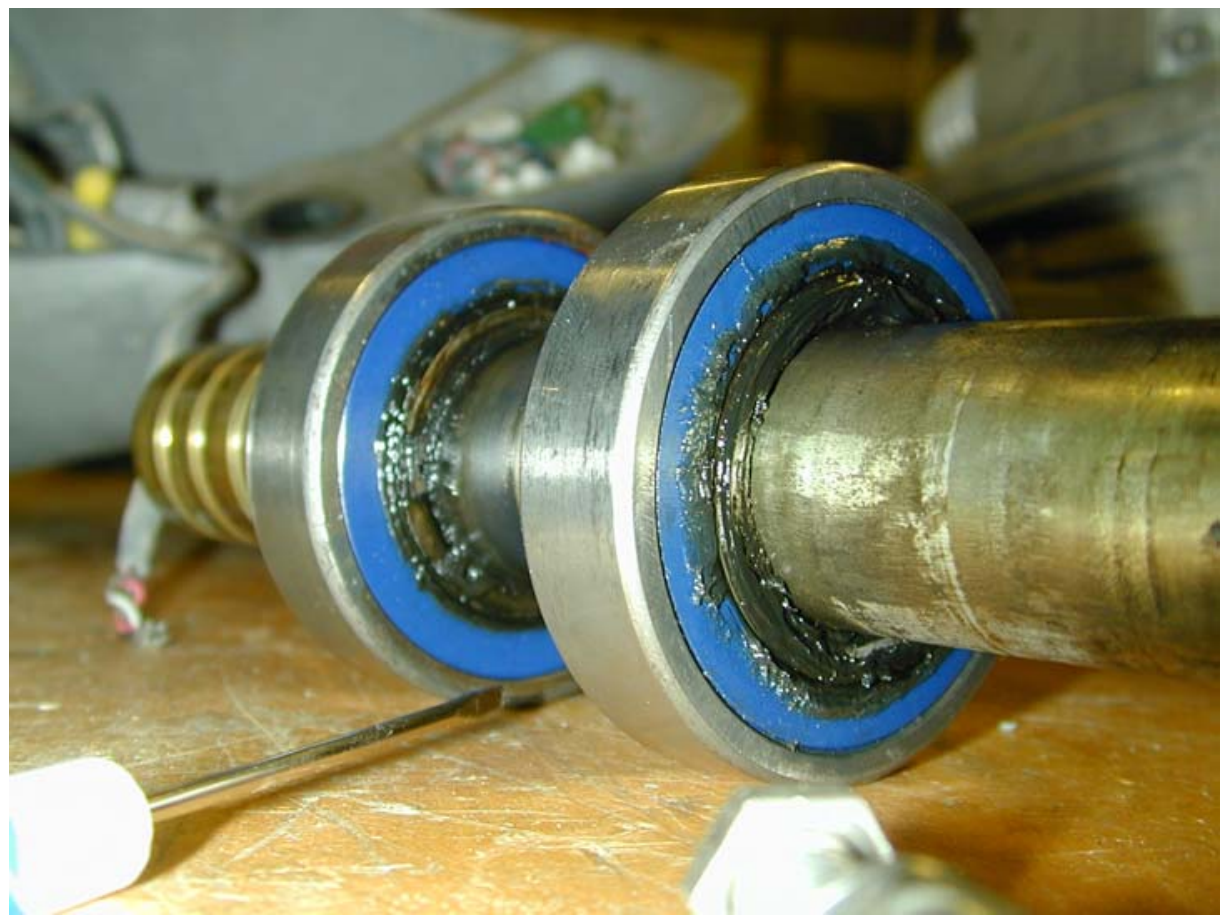

Photo 7. The yaw bearings rotated smoothly and did not show any significant signs of wear but were greasy on the outside. The presence of grease indicates that the seals were starting to fail. 


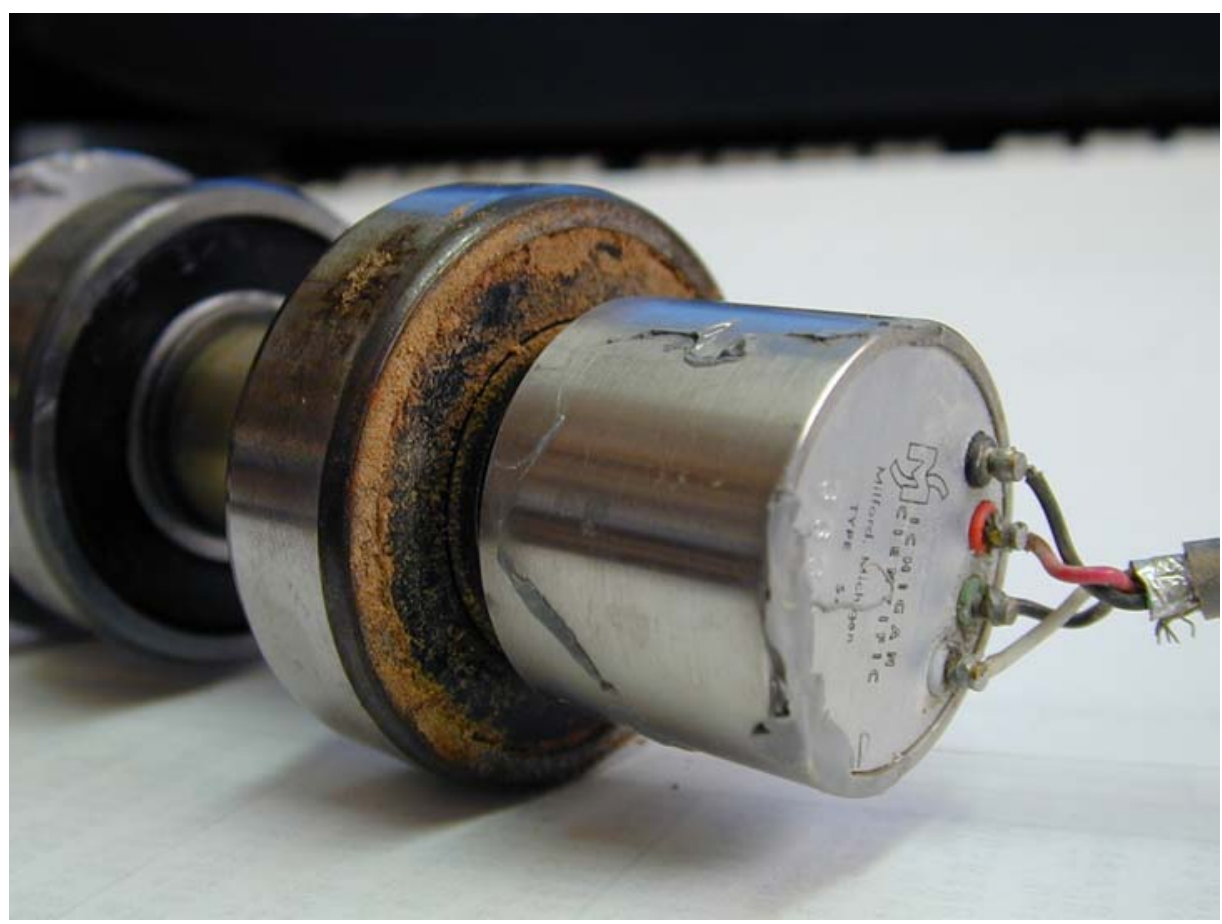

Photo 8. The rotor bearings rotated smoothly and did not show any significant signs of wear. The inner bearing (furthest from the rotor) was rusty indicating that moisture was trapped and made this bearing very difficult to remove. Note that the slipring shown in the photo is not standard. It was used to power a telemetry transmitter for blade load measurements. 


\section{Computer Modeling (ADAMS) and Model Validation:}

An ADAMS model of the Whisper $\mathrm{H} 40$ was built then validated against measured data. This task proved very useful in two primary ways. First we could use the model to broaden our understanding of furling behavior and second we could evaluate the accuracy of the ADAMS model to predict the turbine's behavior. Following is an excerpt from the paper presented at Windpower 2003 [3].

Accurate modeling of a passively furling, variable speed, free yaw (with tailvane), wind turbine is a very complex undertaking requiring the most advanced aero-elastic modeling. Our ADAMS model has 183 degrees-of-freedom where $180 \mathrm{DOF}$ are contained in the flexible beam element blades. The remaining $3 \mathrm{DOF}$ are for the variable speed rotor, free yaw, and a furl hinge.

We have modified the AeroDyn aerodynamic subroutines to calculate the aerodynamic force on the tailvane. This tail force is necessary to keep the rotor upwind and because it is a key component in defining the turbine yawing behavior. Although we account for some reduction in the airstream velocity behind the rotor (where the tail is located) we understand this is a simplified approach to a complex aerodynamic problem.

Another difficulty in modeling a passively furling wind turbine is the interdependency of many of the key drivers of the furling behavior. For example, if one incorrectly models the generator torque-speed characteristic the model will not accurately

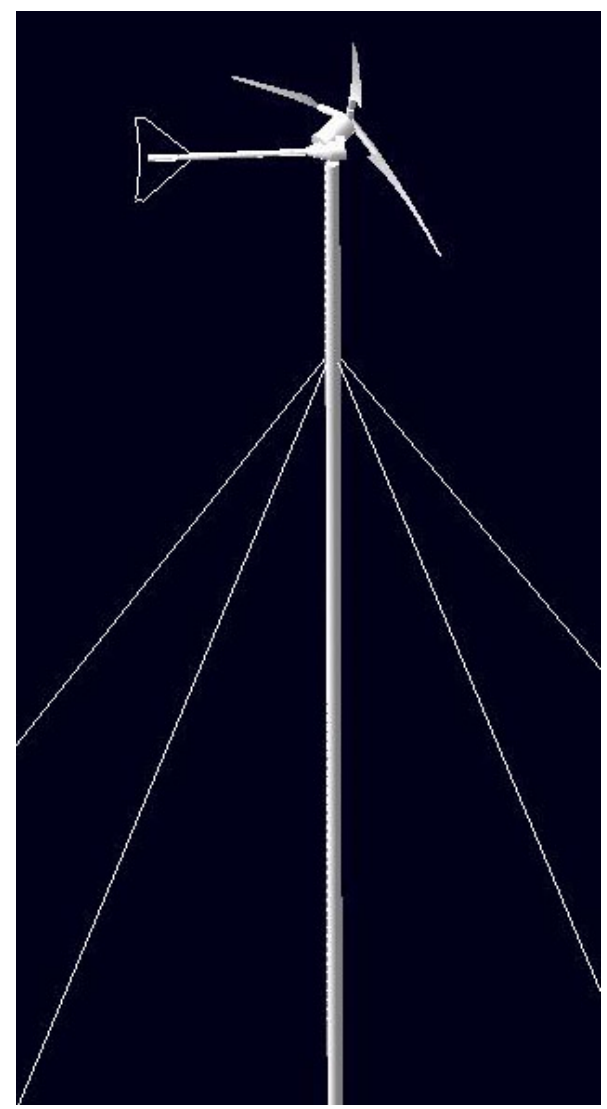
predict the rotor speed. This will result in inaccuracies in the rotor aerodynamics, which in turn will result in an error of the furl angle prediction. Inaccuracies in the furl prediction will feed back into rotor speed and other areas such as yaw angle, further decreasing the accuracy of the model prediction. Unfortunately, we rarely know that the problem lies in the generator torque-speed characteristic, as was given in the above example. What we see is that the rotor speed prediction is too high and that the furl angle prediction is too low. We can't be certain whether the rotor speed is too high and the aerodynamic forces and moments are forcing the furl angle too low, or whether the furl angle is too low thereby allowing the rotor speed to be too high.

With all of the known difficulties we feel overall the ADAMS model predicts the turbine behavior well, as shown in the time series comparisons in Figures $11-18$. These figures are comparisons between test data and ADAMS model predictions for a 10-minute period of moderately high winds. Within this 10 -minute time series the winds varied from $8 \mathrm{~m} / \mathrm{s}$ to $17 \mathrm{~m} / \mathrm{s}$ with a mean wind speed of $13 \mathrm{~m} / \mathrm{s}$ and turbulence intensity of $12 \%$.

These figures are grouped in pairs where the first figure shows the 10-minute time series comparison while the second figure shows a smaller (200-second) segment, between 100 and 300 seconds, so that more detail can be seen. This section was chosen since it shows a portion where the model is predicting turbine behavior closely (first half) as well as a section where the model prediction is starting to stray from the measured test data (second half). This highlights a trend that we are seeing with the model validation, which is that the model rotor tends to furl too little in the higher winds. Comparisons to a higher wind data set are shown later, highlighting these differences.

Figures 19 - 22 show the load comparisons between the ADAMS model predictions and the measured test data. The tower bending loads are very similar to the turbine performance plots where the overall predictions match well but stray when other turbine characteristics such as rotor speed start to drift away 
from the measured values. On the other hand, the blade root flap bending moment predicted by ADAMS is approximately double that seen in the test data. To date we have not been able to determine the cause of this discrepancy. Although there are numerous reasons why the model would over-predict the measured value (one example being inaccuracies in the airfoil lift and drag characteristics), it is difficult to reconcile how the flap moment could be significantly different when most other turbine parameters and loads are being predicted accurately. We have investigated many possibilities, from an error in the instrumentation calibration to an edge-to-flap moment cross talk in the strain gage calibration. None of our investigations have been able to explain this difference. At this point we feel it is most likely coming from a relatively small error (or number of small errors) which are being magnified because the blade root flap moment is the difference of two large opposing moments: the aerodynamic flap moment and the opposing centrifugal moment. We believe the aerodynamic flap moment must be close for us to be getting good power and tower bending predictions and as a result we are most suspicious of the blade mass properties used in the modeling. Calculations have shown that a $10 \%$ error in the blade flapping inertia would reduce the current error seen in the flap moment predictions by as much as $50 \%$. Although the blade mass properties were carefully measured, approximations and assumptions were necessary and may have introduced errors. Another area where errors could have been introduced is from the fact that the blade being flown is not the blade that was measured. The measured blade was destroyed (cut) in order to more accurately measure the mass properties.

As mentioned before, the ADAMS simulation is tending to under-predict the furl angle in high winds. The model also appears to over-predict the rotor speed which we feel is partly because of the lower furl angle and partly the reason for the lower furl angle, since the un-furling rotor moment will often increase when the rotor is allowed to rotate faster. Figures $23-27$ show simulation to test data comparisons for a high wind test case where the average wind speed (for the entire 10 -minute period) is $16.3 \mathrm{~m} / \mathrm{s}$. The minimum wind speed for the test case is $11.5 \mathrm{~m} / \mathrm{s}$ and the maximum is $21.2 \mathrm{~m} / \mathrm{s}$ with a reasonably low turbulence intensity of $10 \%$. The two areas that we feel are most likely causing the inaccuracies are listed below:

1) We don't have a reliable torque vs. speed curve for our test turbine alternator and load. We did receive results of a bench test of the generator torque speed curve and efficiency curve from Southwest Windpower (SWWP). However, the output power vs. speed curve that we measure (with our load) differs from the data provided by SWWP. We assume this is a result of different electrical loads in the two tests, but we are unable to confirm this hypothesis. We used our measured power vs. speed curve and the SWWP efficiency curve (extrapolated beyond rated power) to estimate the input torque vs. speed curve for our modeling. With a bench test generator efficiency of $56 \%$ at rated power it is easy to understand how estimations and assumptions in our input torque speed curve can dramatically influence the model accuracy.

2) The high wind comparisons result in high furl angles. These high furl angles translate to high yaw errors, i.e. high rotor skew angles. The rotor aerodynamics do change characteristics at these high skew angles and little validation of the aerodynamic modeling codes has been done for this operating condition. As a result we believe that the rotor aerodynamics could be causing some of the differences we are seeing. 


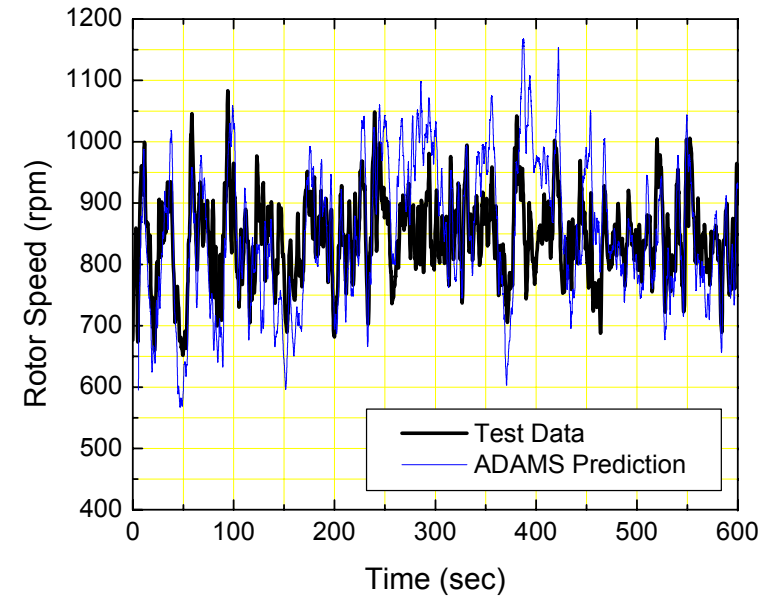

Figure 11. Rotor speed comparison between measured test data and the ADAMS prediction.

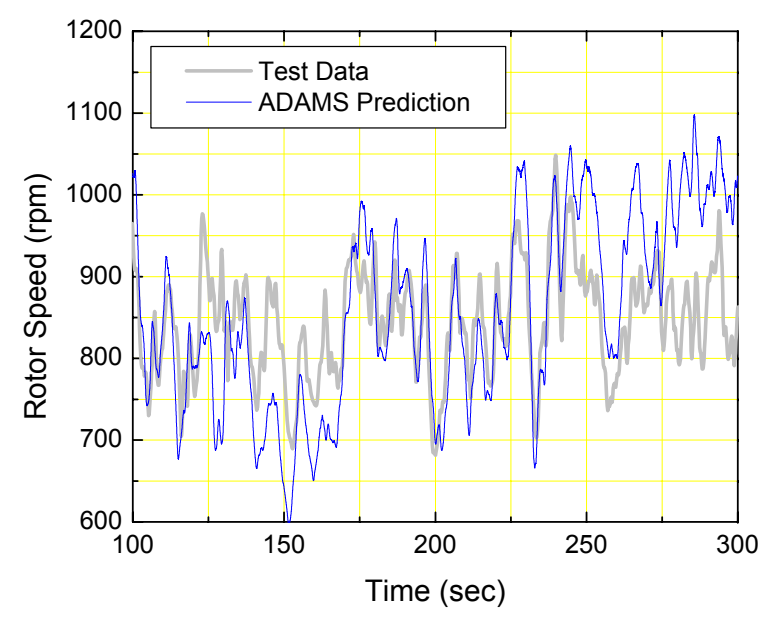

Figure 12. A 200 second segment of the comparison shown in Figure 11.

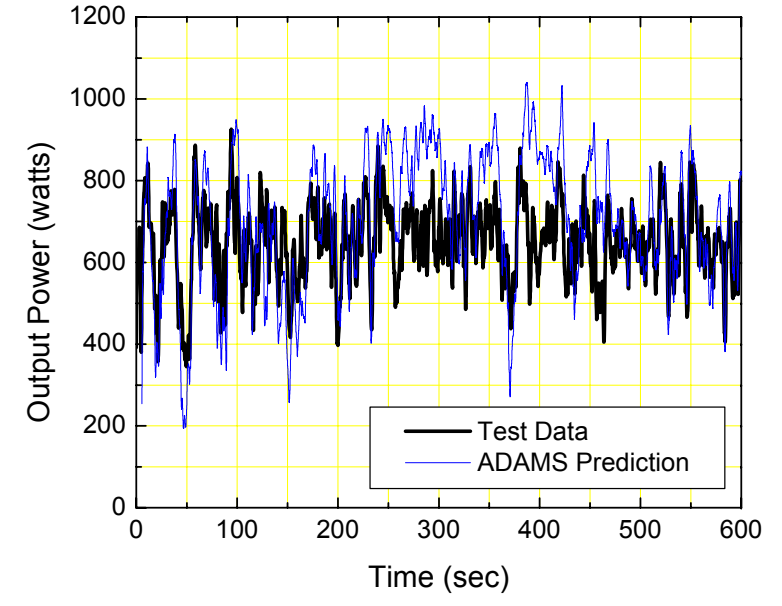

Figure 13. Output power comparison between measured test data and the ADAMS prediction.

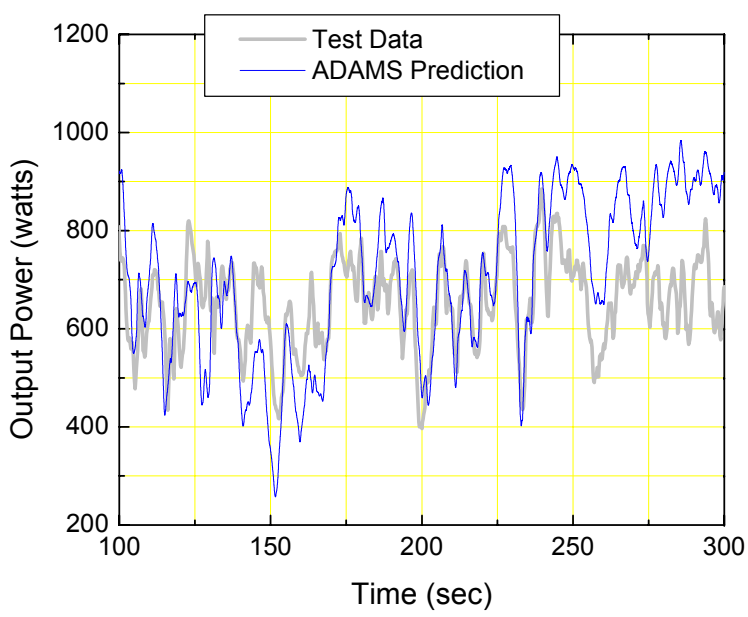

Figure 14. A 200 second segment of the comparison shown in Figure 13. 


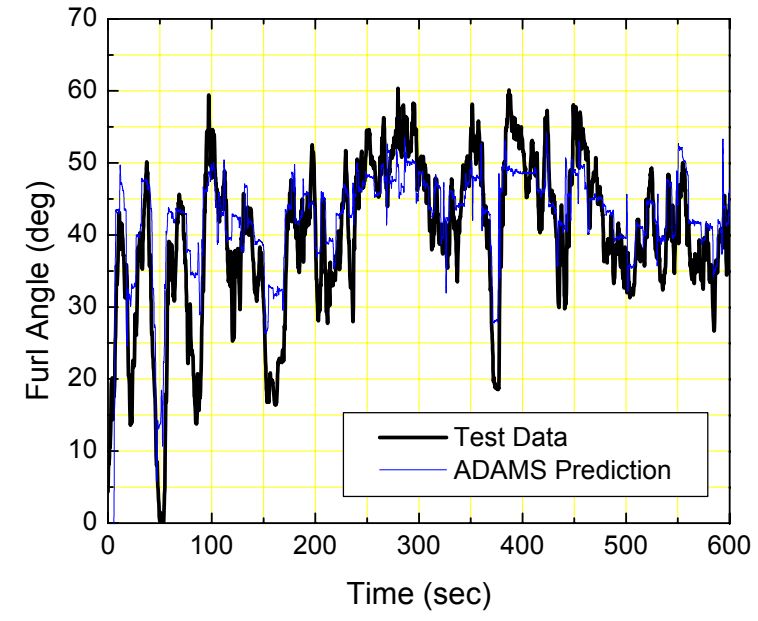

Figure 15. Furl angle comparison between measured test data and the ADAMS prediction.

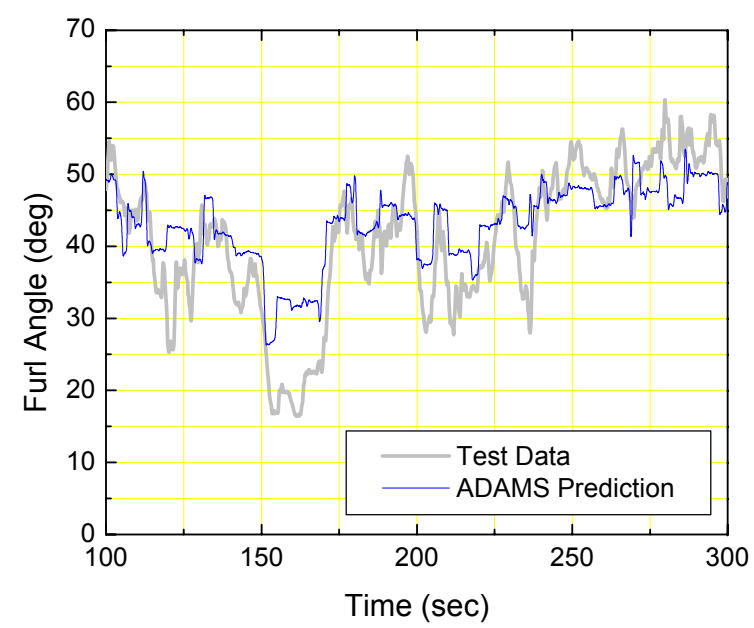

Figure 16. A 200 second segment of the comparison shown in Figure 15.

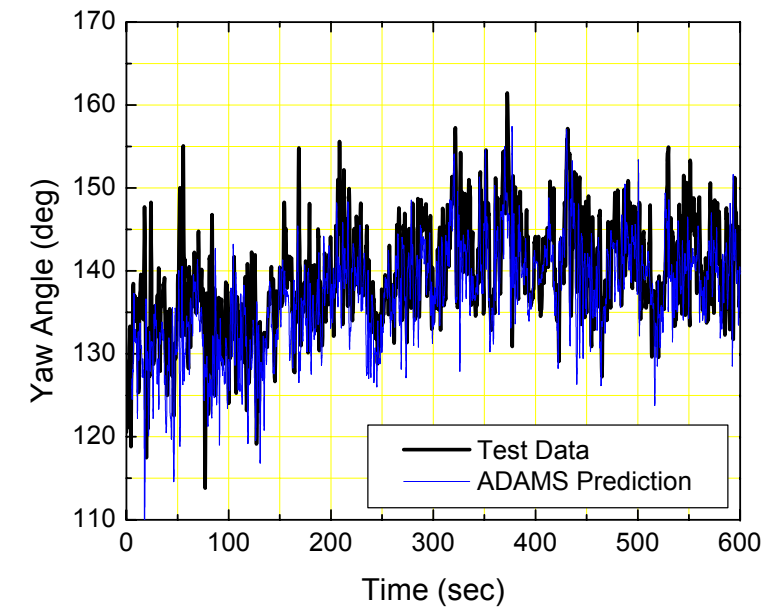

Figure 17. Yaw Angle ${ }^{3}$ comparison between measured test data and the ADAMS prediction.

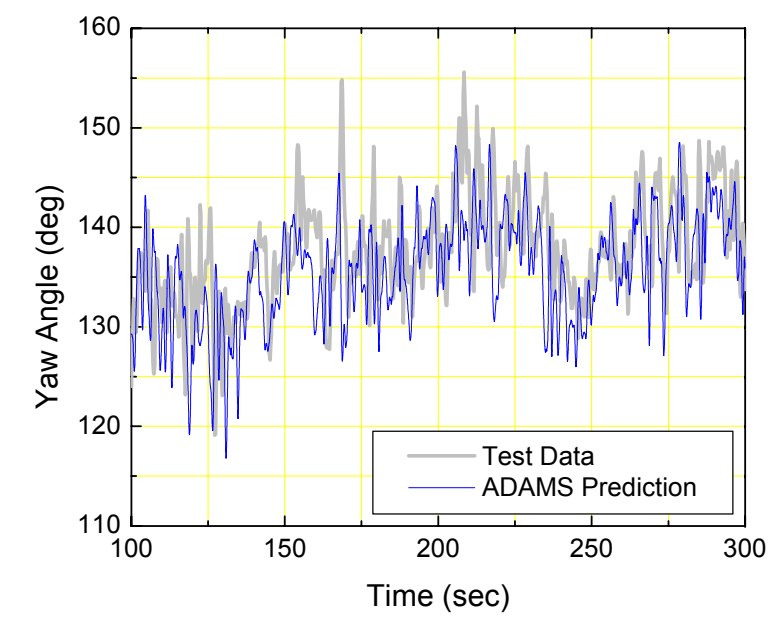

Figure 18. A 200 second segment of the comparison shown in Figure 17.

${ }^{3}$ Yaw angle is the angle of the tail, not the rotor. The rotor yaw angle (angle at which the rotor axis-of-rotation is pointing) is the yaw angle minus the furl angle for this turbine configuration. 


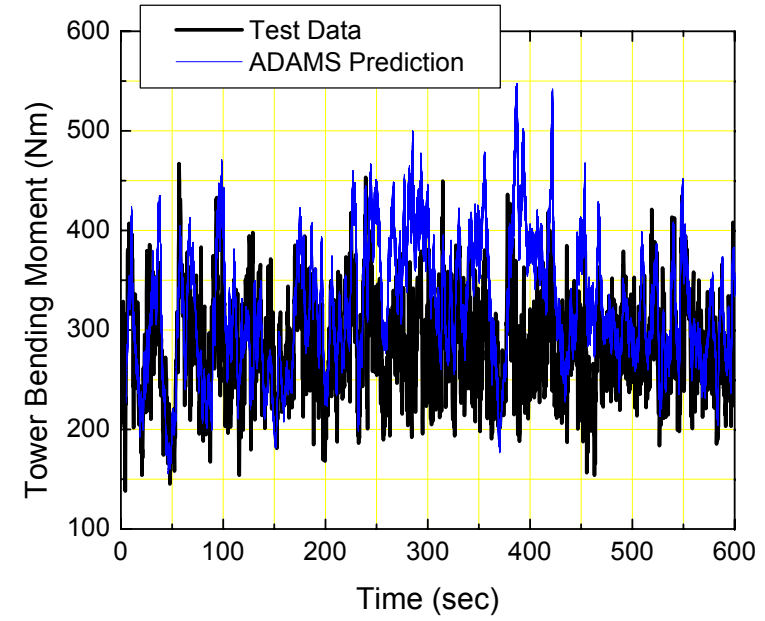

Figure 19. Tower moment magnitude comparison between measured test data and the ADAMS prediction.

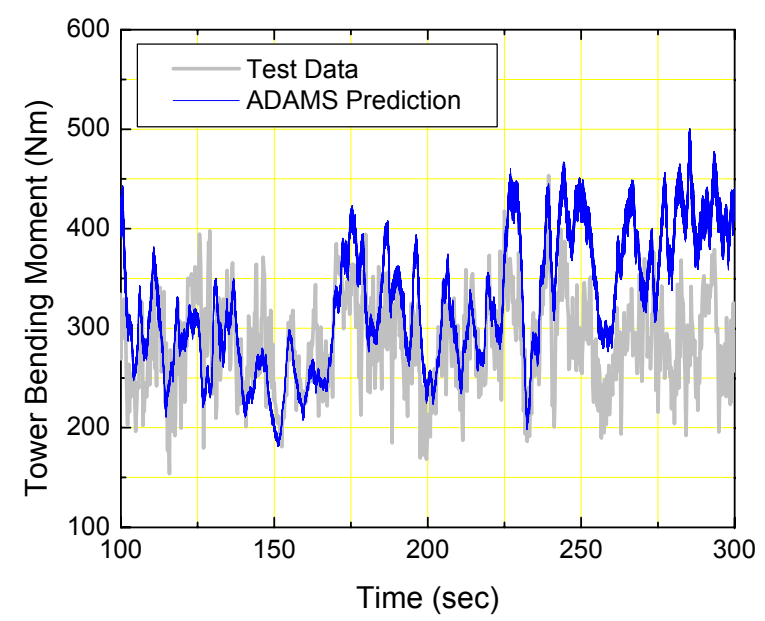

Figure 20. A 200 second segment of the comparison shown in Figure 19.

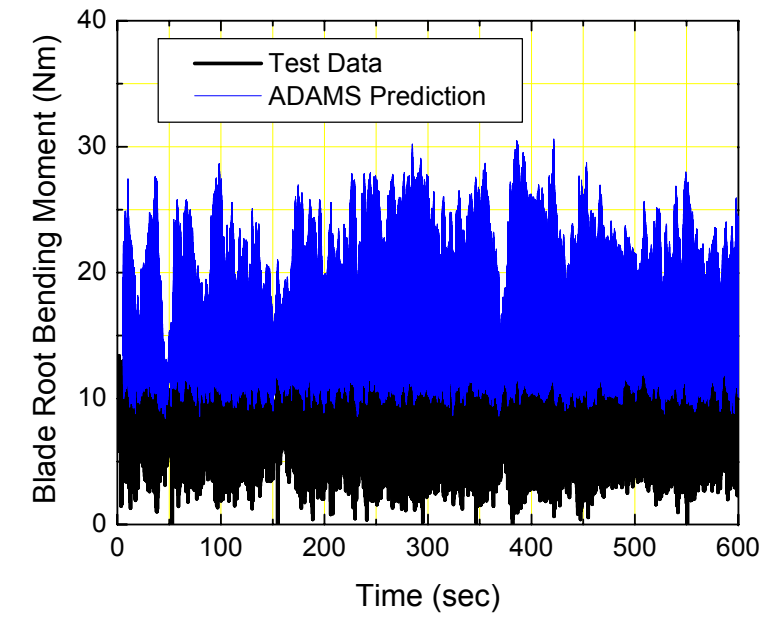

Figure 21. Flap moment comparison between measured test data and the ADAMS prediction.

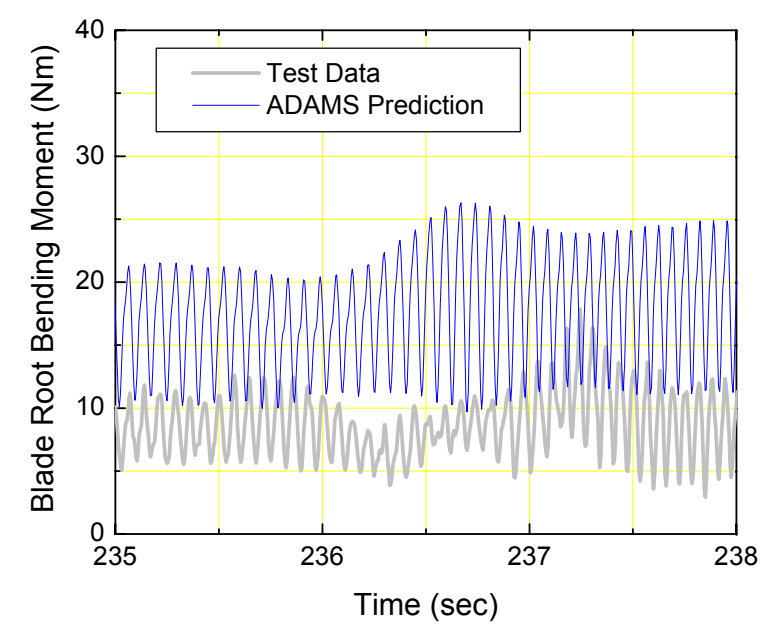

Figure 22. A 3 second segment of the comparison shown in Figure 21 . 


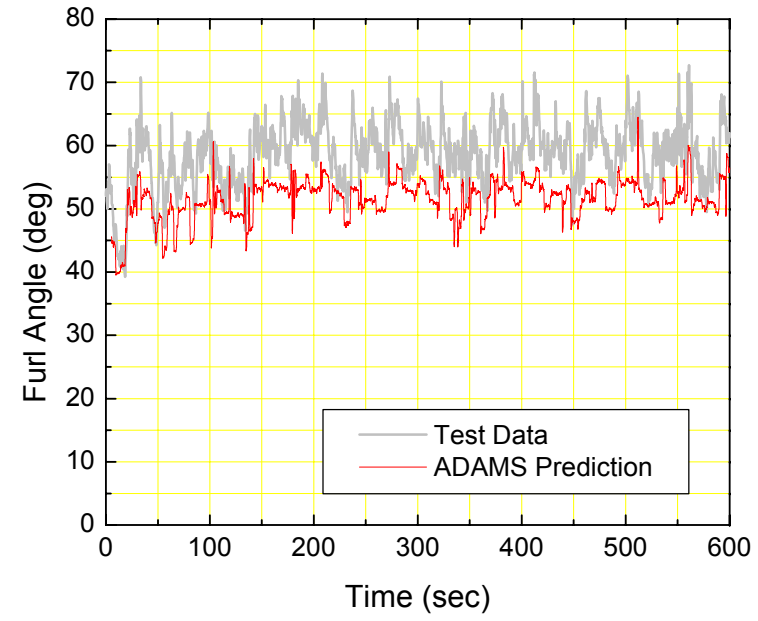

Figure 23. Furl angle comparison between measured test data and the ADAMS prediction for the high wind test case.

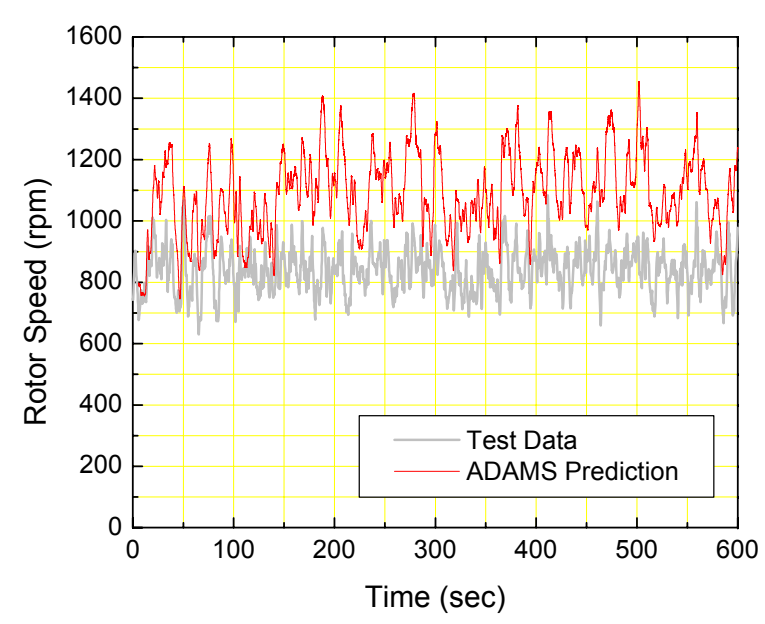

Figure 24. Rotor speed comparison between measured test data and the ADAMS prediction for the high wind test case.

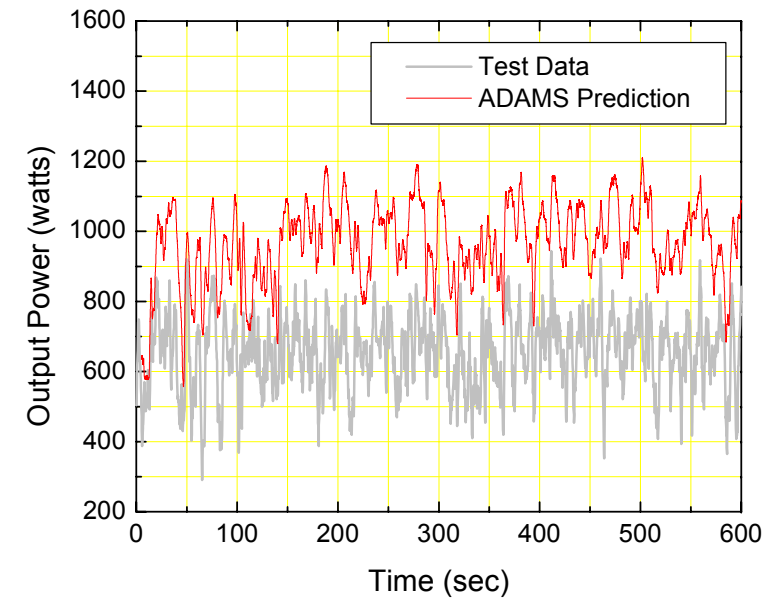

Figure 25. Output power comparison between measured test data and the ADAMS prediction for the high wind test case.

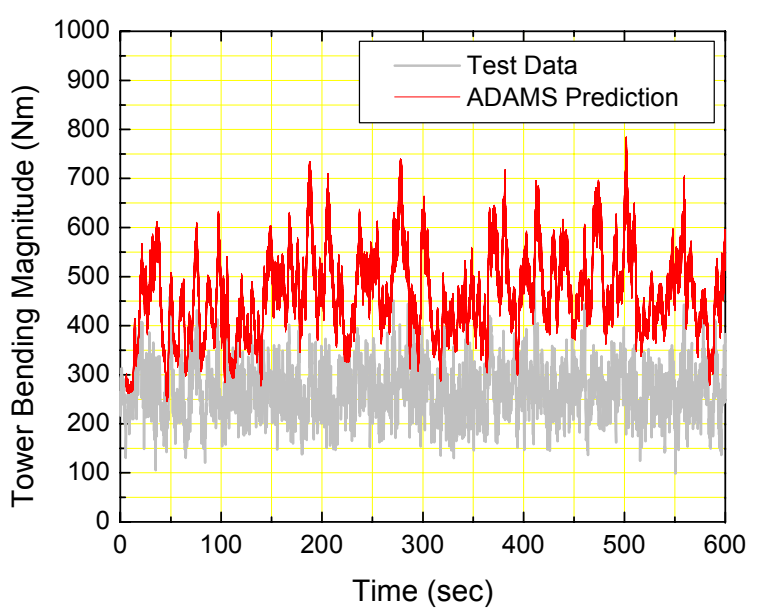

Figure 26. Tower bending moment comparison between measured test data and the ADAMS prediction for the high wind test case. 


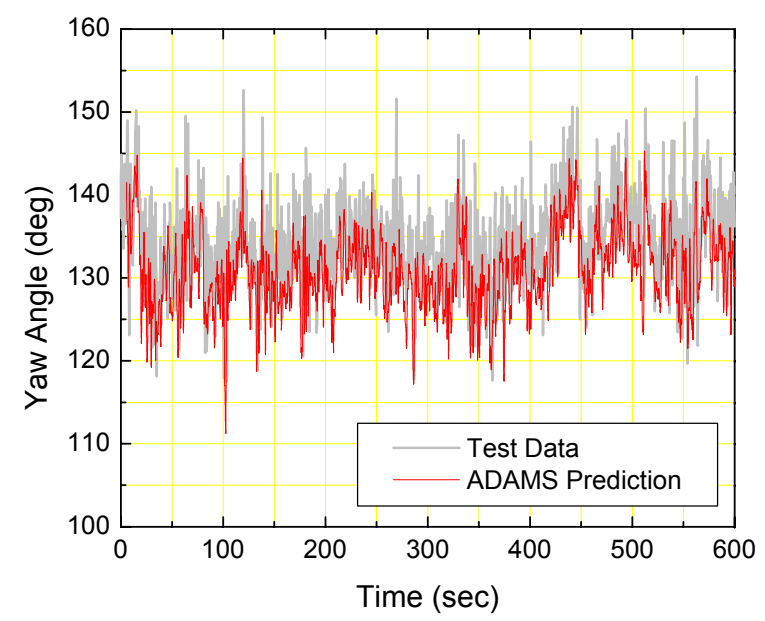

Figure 27. Yaw angle comparison between measured test data and the ADAMS prediction for the high wind test case. 


\section{Turbine Operation During Extreme Wind Events:}

Although there has been long-term wind data collected at the site these data were 10-minute averages and as a result the frequency of short-term "extreme" wind events has not been quantified. From our observations these extreme winds happen most often during the hotter months of the year when thunderstorms build to the east, above the higher elevations. Although it is not uncommon to have dozens of events where the winds are gusting above $22 \mathrm{~m} / \mathrm{s}$ (at hub height) we typically only expect one of these high wind events (per year) to generate winds that approach the IEC extreme wind events. Although these winds are not ideal for wind energy production they are interesting for an experimental wind research facility. In May of 2002 we captured some gusts that were similar to the IEC extreme winds. These data show how the turbine responded (dynamics and turbine loads) to the gust and has given insight into what type of wind events are most problematic for a passively furling wind turbine. Following is an excerpt from the paper presented at Windpower 2002 [2] which focused on the turbine operation during extreme wind events.

In May of 2002 data were collected during a weather pattern where extreme gusty winds were occurring. These winds are a deviation from the normal canyon flow but do occur somewhat regularly during the thunderstorm season (spring and summer). Three separate events, each one showing either an extreme wind events or high turbine loading, were extracted from the data set. The first event is an extreme wind event that is similar to the IEC 50-year Extreme Operating Gust (EOG). This event has a steep increase in wind speed $(\sim 10 \mathrm{~m} / \mathrm{s}$ above the rated wind speed) in a relatively short ( $\sim 4$ seconds) period (see Figure 28$)$. The second event is another extreme wind event; this one more closely matches the IEC Extreme Coherent Gust (ECG). This event has a higher gust speed ( $\sim 15 \mathrm{~m} / \mathrm{s}$ above the rated wind speed) but the rise time is longer ( $\sim 10$ seconds) (see Figure 33 ). The third wind event is less extreme but it is included because it resulted in high blade loading. It consists of turbulent high wind between 16 and $18 \mathrm{~m} / \mathrm{s}$ (see Figure 37).

We also captured a wind event in the winter of 2002 that surprisingly resulted in some extreme turbine loading and the highest recorded rotor speed (Figures 41-44). Although this wind event was a fast-rising gust it did not appear as severe as an IEC extreme gust. Discovering this high rotor speed and high loads, during a "less than IEC gust" sheds light on the fact that the highest loading for a passively furling turbine is not based only on the wind input but also highly dependent on the initial operating state of the turbine. Plots from this event are shown below and compared to the IEC type gusts in the section titled "Summary of Extreme Wind Events".

\section{IEC 50-year Extreme Operating Gust (EOG):}

Figures 28 through 32 show the EOG wind event and the turbine response to that event. Figure 29 shows that the turbine is hit by the gust while the turbine is in an unfurled state. This results in a rapid increase in the rotor speed with a peak rotor speed of $1367 \mathrm{rpm}$. The turbine then rapidly furls (to a fully furled angle of $73^{\circ}$ ) causing the rotor speed to drop even as the wind speed stays above $15 \mathrm{~m} / \mathrm{s}$. This extreme wind event combined with the high rotor speed resulted in high tower bending moments. The magnitude of the two bending moments on the tower was almost $700 \mathrm{Nm}$ (Figure 30). At the time of this event this was the highest tower bending moment recorded to date. Figures 31 and 32 show the blade root bending moment loading during the EOG event. Although this loading is high this loading is not as high as recorded during other wind conditions.

\section{IEC Extreme Coherent Gust (ECG):}

Figures 33 through 36 show the ECG wind event and the turbine response to that event. Similar to the start of the EOG case, Figure 34 shows that the turbine is hit by the gust while the turbine is in an unfurled state. This again results in a rapid increase in the rotor speed with a peak rotor speed of $1324 \mathrm{rpm}$. The turbine then rapidly furls and the rotor speed drops. This extreme wind event combined with the high rotor speed similarly resulted in high tower bending moments (Figure 35), although less than measured during the EOG event. Figure 36 shows the blade root bending moment loading during the ECG event. It is interesting to note that the highest blade loading $(22 \mathrm{Nm})$ did not occur during the ECG type gust (event at $\sim 35$ seconds) but instead during a smaller gust and at much lower rotor speeds (event at $\sim 25$ seconds).

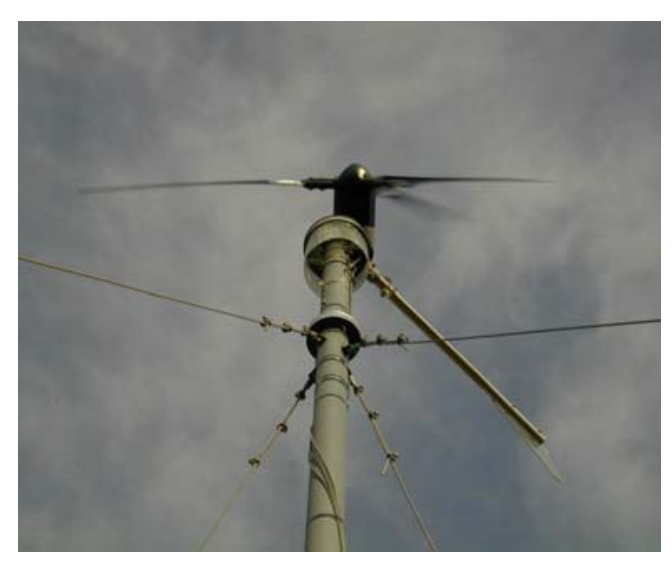




\section{Turbulent high wind operation:}

Figures 37 through 40 show operation of the turbine during turbulent high winds. Figure 37 shows the wind speed and wind direction for a short 5 -second period. Figure 38 shows that during these winds the turbine is furled above $60^{\circ}$ (with little change) and the rotor speed is shown to be below $850 \mathrm{rpm}$ at all times. Although this wind would appear to be benign in comparison to the first two examples we are measuring high root flap bending loads during this event. These high flap loads appear to be a result of the corresponding high yaw-rates. This correlation is shown in Figure 39. Figure 40 shows that these winds produce considerably lower tower bending loads when compared to the previous two events.

\section{Highest Recorded Rotor Speed:}

Figures 41 through 44 show the wind speed, turbine operation, and loads measured during a gusty wind event. Figure 41 shows that within a 50 second period of time the wind had three steep rise gusts. The first gust being the only gust that generated any significant turbine response since after the first gust the turbine was fully furled and not vulnerable to the high gusty winds that followed. Figure 42 shows that the measured wind speed had a similar rise time to the IEC EOG 1-year gust but that the peak wind speed was considerably lower than found in the IEC case. Figure 43 shows how the gust hits with the turbine nearly unfurled and how the rotor speed responds with a very fast acceleration to the gust. This event produced the highest recorded rotor speed for the entire project (1534 rpm or $\sim 210 \%$ of rated). Figure 43 also shows how the turbine fully furled soon after the high rotor speed event. Figure 44 show that the high rotor speed translated into a high tower bending moment. This was the highest tower bending moment measured during the entire test period.

\section{Summary of extreme wind events:}

Table 3 summarizes the maximum loads from the above four wind events. These extreme wind events, and the turbine response gave insight into which wind events would most likely generate the highest loading. From review of these cases we speculate the following:

1. The higher rotor speeds will come from a fast-rise gust that commences while the turbine is unfurled. If the turbine is highly furled at the onset of the gust, the peak rotor speed will not be as high.

2. The maximum tower bending load appears to be highly dependent on the rotor speed, i.e. the higher the peak rotor speed the higher the tower bending load.

3. The high rotor speeds may result in relatively benign blade (out of plane) bending loads due to centrifugal stiffening.

4. High yaw rates can generate high blade (out of plane) bending loads.

Table 3. Maximum recorded values during four extreme wind events.

\begin{tabular}{lclccc}
\hline $\begin{array}{l}\text { Wind } \\
\text { Condition }\end{array}$ & $\begin{array}{l}\text { Maximum } \\
\text { Rotor Speed } \\
(\mathbf{r p m})\end{array}$ & $\begin{array}{l}\text { Furl Angle } \\
\text { During Event } \\
(\mathbf{d e g})\end{array}$ & $\begin{array}{l}\text { Maximum } \\
\text { Yaw Rate } \\
(\% / \mathbf{s e c})\end{array}$ & $\begin{array}{l}\text { Maximum } \\
\text { Blade Root } \\
\text { Bending } \\
\text { Moment (Nm) }\end{array}$ & $\begin{array}{l}\text { Maximum } \\
\text { Tower Bending } \\
\text { Moment (Mag.) } \\
(\mathbf{N m})\end{array}$ \\
\hline $\begin{array}{l}\text { Similar EOG } \\
(50 \text {-yr.) }\end{array}$ & 1367 & Between 0 \& 73 & 39 & 17.7 & 687 \\
\hline Similar ECG & 1324 & Between 0 \& 73 & 86 & $22.1 *$ & 575 \\
\hline $\begin{array}{l}\text { Turbulent High } \\
\text { Winds }\end{array}$ & 878 & Between 60 \& 65 & 57 & 21.1 & 425 \\
\hline $\begin{array}{l}\text { Gusty wind -less } \\
\text { than EOG (1-yr.) }\end{array}$ & 1534 & Between 0 \& 73 & 71 & 15.0 & 723 \\
\hline
\end{tabular}

*Highest blade root bending moment occurred at a rotor speed of less than $900 \mathrm{rpm}$. 


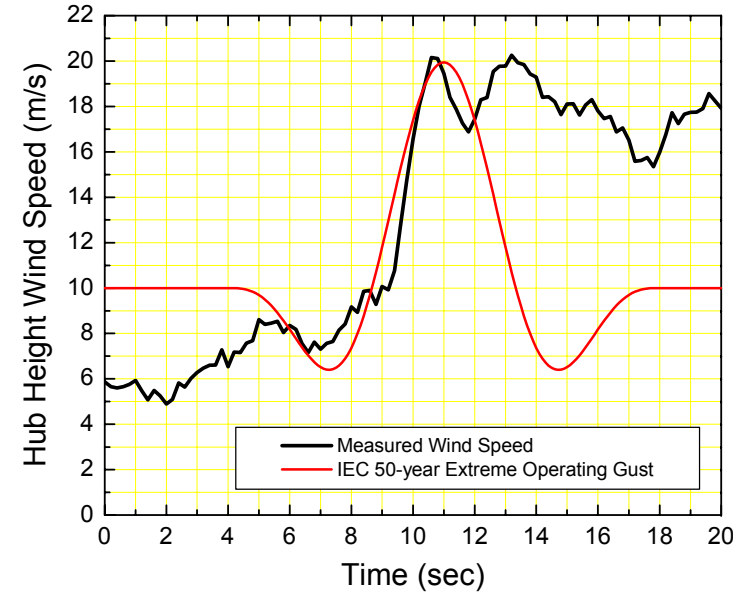

Figure 28. Wind speed captured which is similar to the IEC 50year Extreme Operating Gust (EOG)

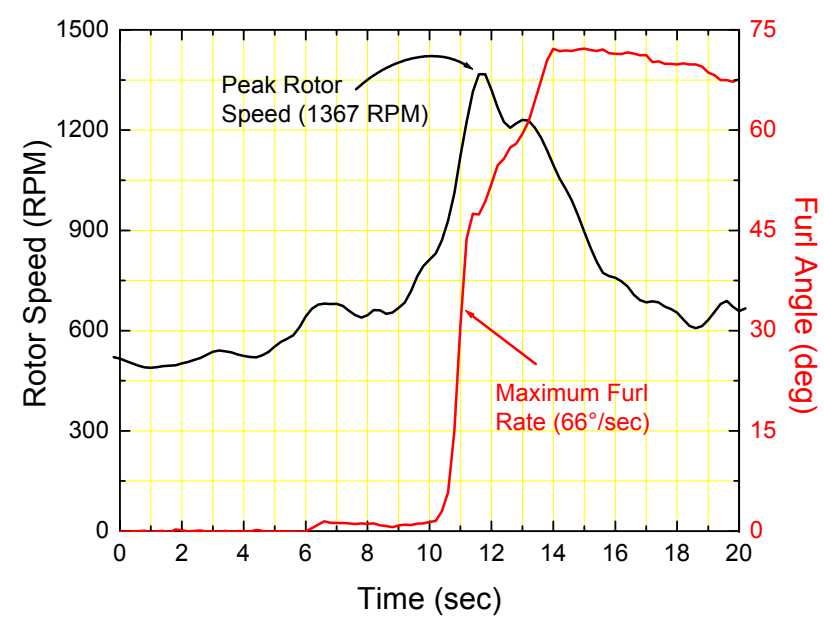

Figure 29. Turbine response due to the EOG extreme wind event.

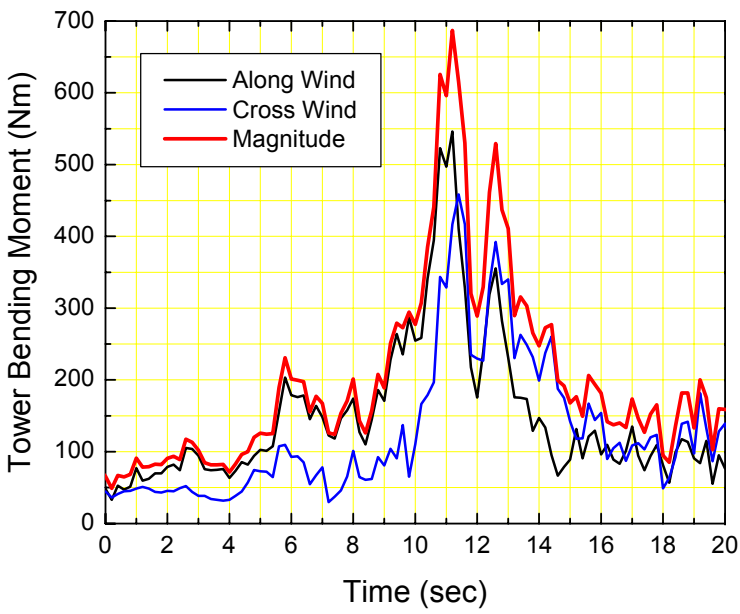

Figure 30. Tower bending moments due to the EOG extreme wind event.

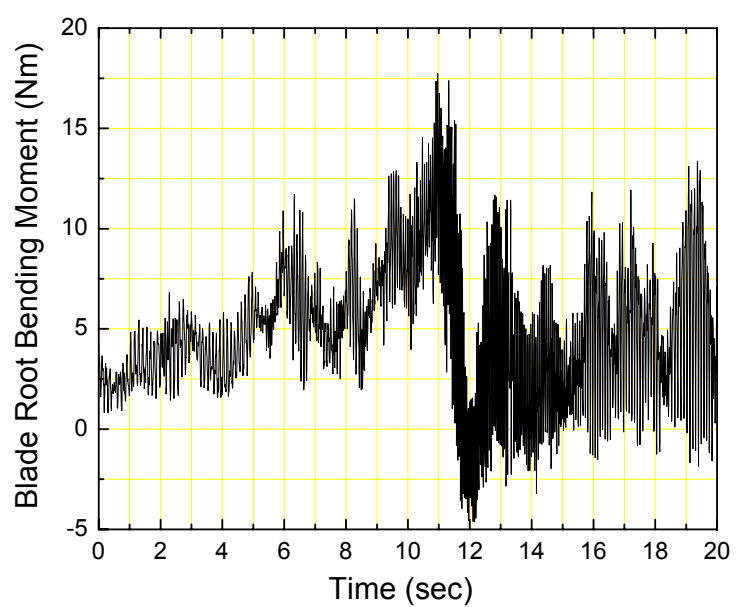

Figure 31. Blade root bending moment due to the EOG extreme wind event. 


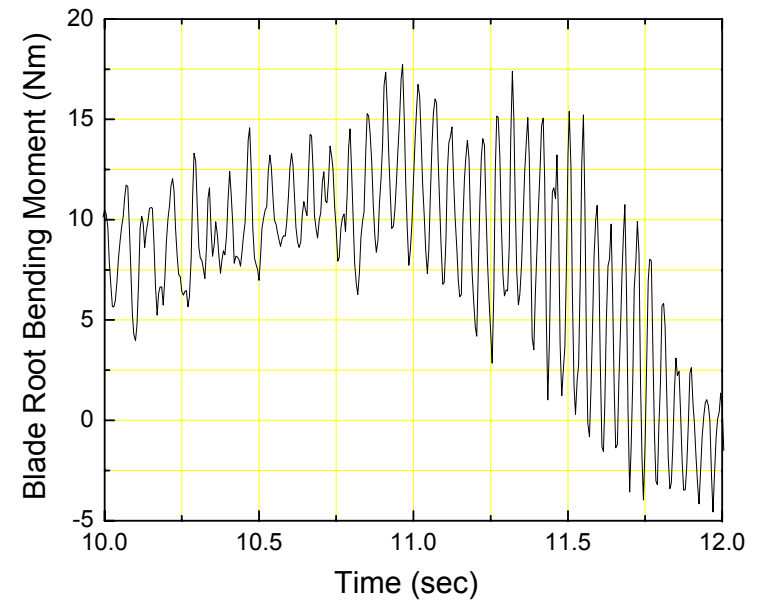

Figure 32. Zoomed view of peak loading seen in Figure 31 (blade root bending moment)

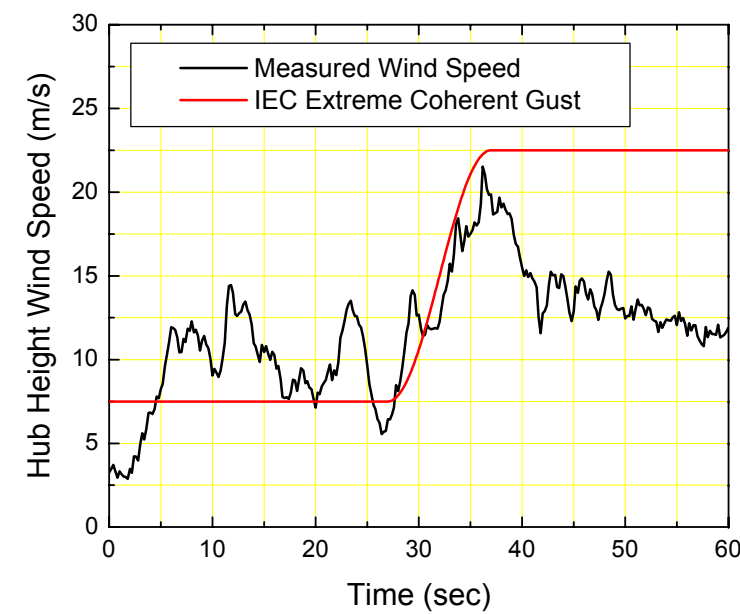

Figure 33. Wind speed captured which is similar to the IEC Extreme Coherent Gust (ECG).

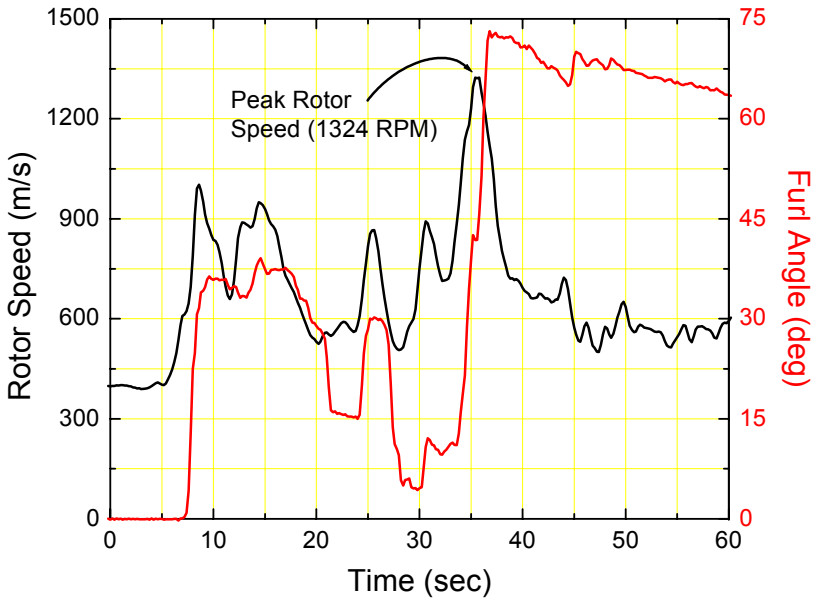

Figure 34. Turbine response due to the ECG extreme wind event.

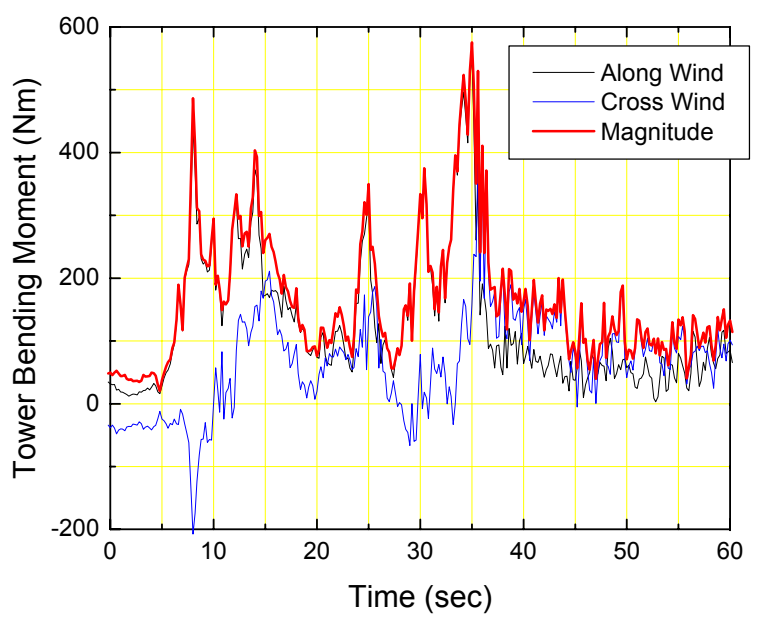

Figure 35. Tower bending moments due to the ECG extreme wind event. 


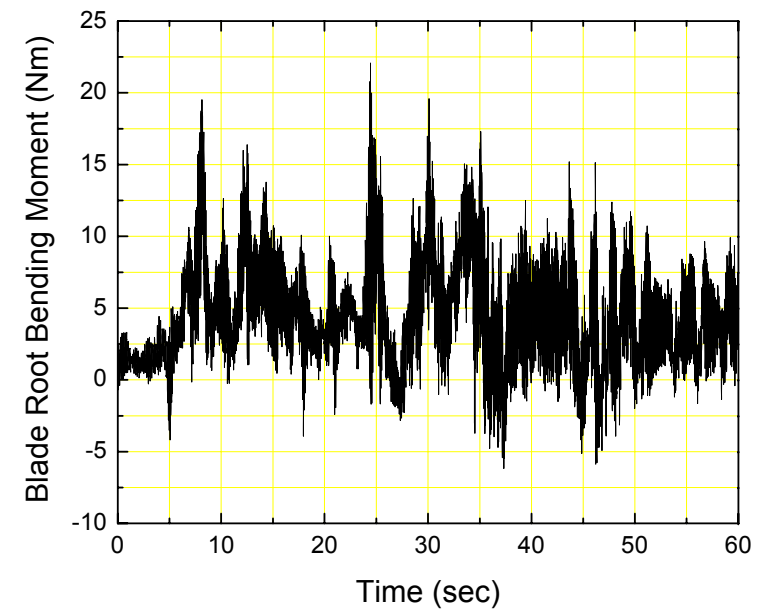

Figure 36. Blade root bending moment due to the ECG extreme wind event.

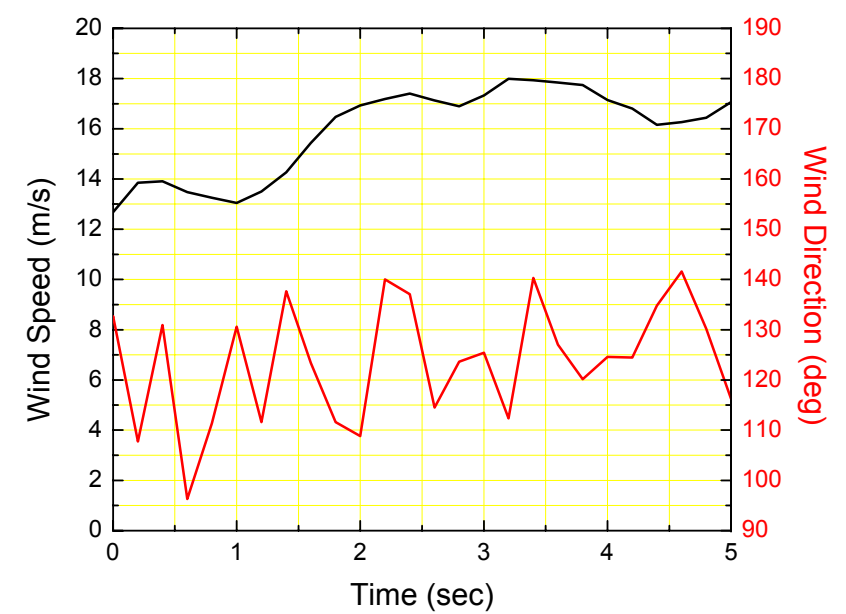

Figure 37. Wind speed shown along with wind direction for the turbulent high wind.

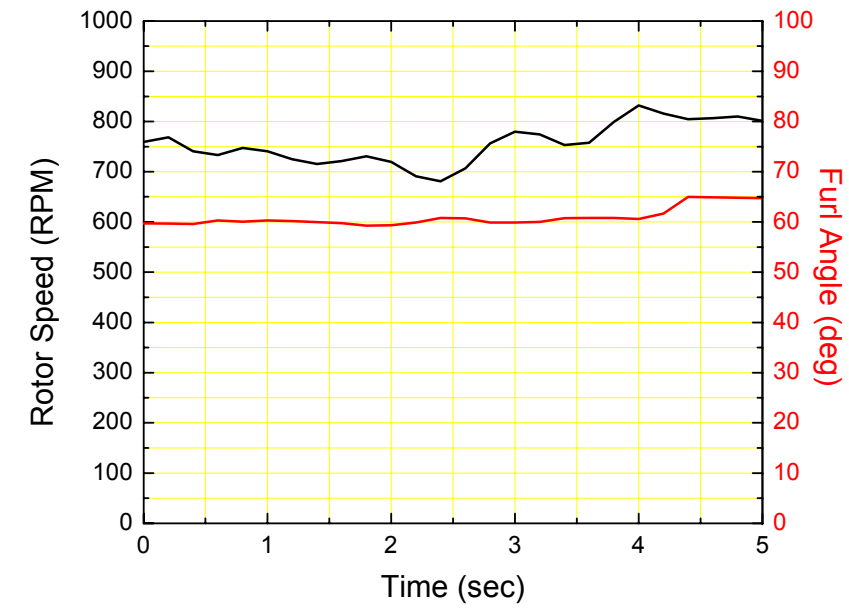

Figure 38. Turbine response during the turbulent high winds.

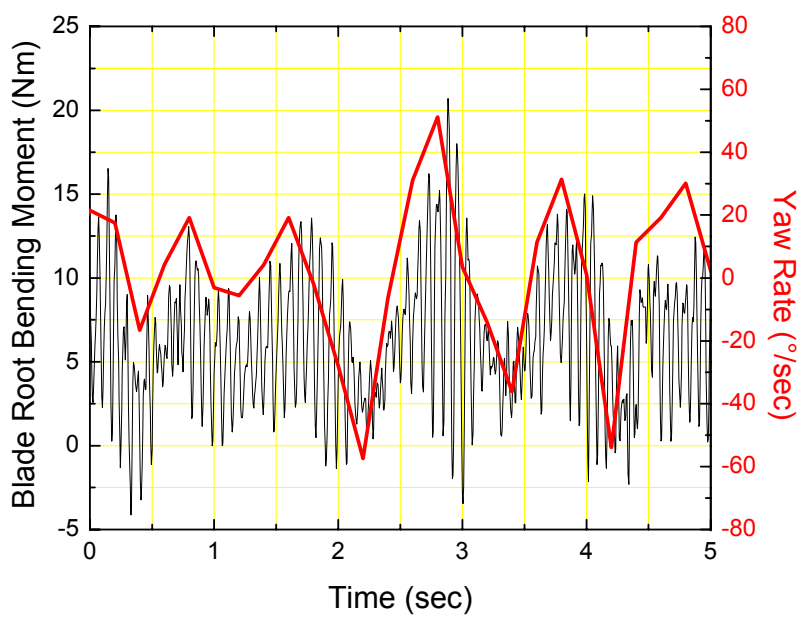

Figure 39. Root flap bending moments and yaw rate during the turbulent high winds. 


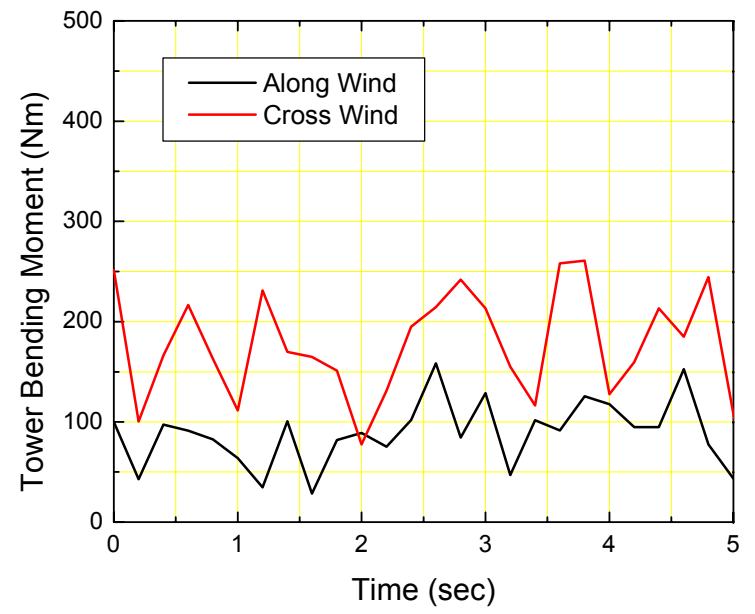

Figure 40. Tower bending moments during the turbulent high winds.

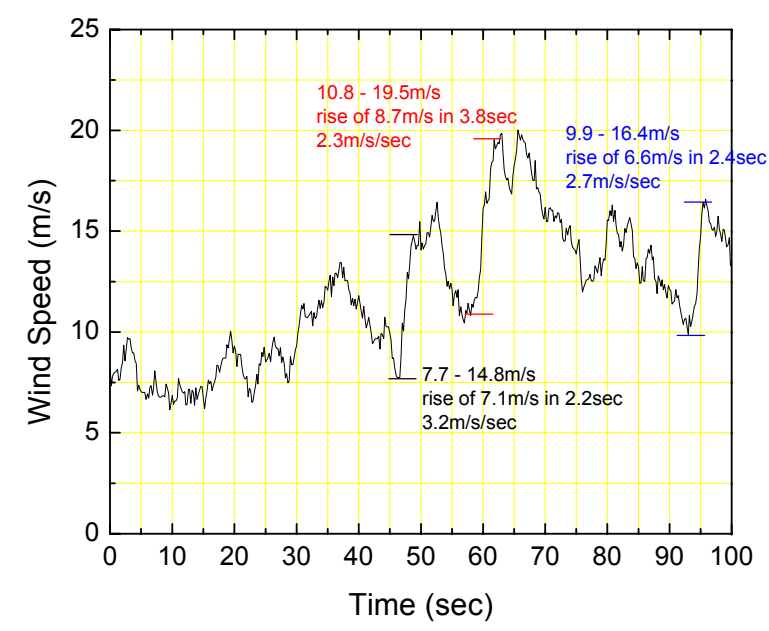

Figure 41. Wind speed time series which generated the highest measured rotor speed. Note that the initial gust was followed with similar gusts that resulted in a benign turbine response.

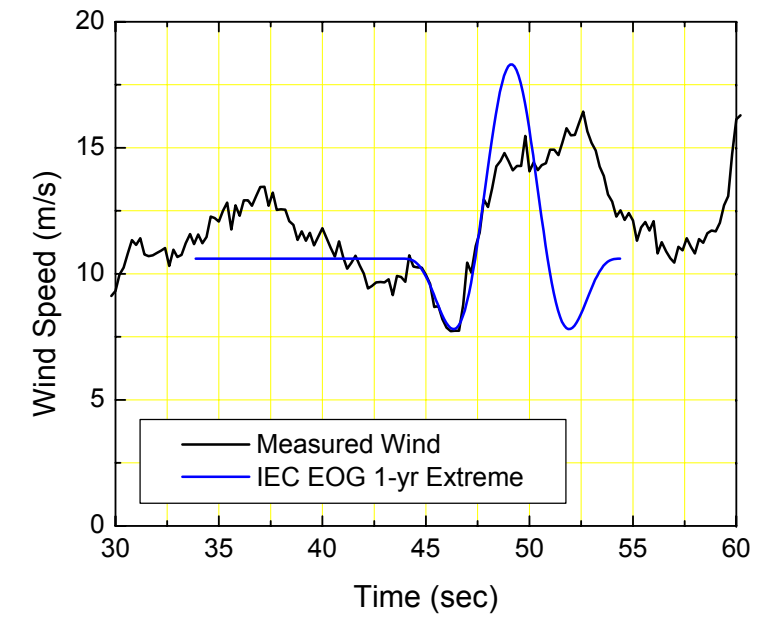

Figure 42. Measured wind speed compared to an IEC EOG 1year extreme gust. Note that wind direction is not shown since the sensor was out of commission during the gust.

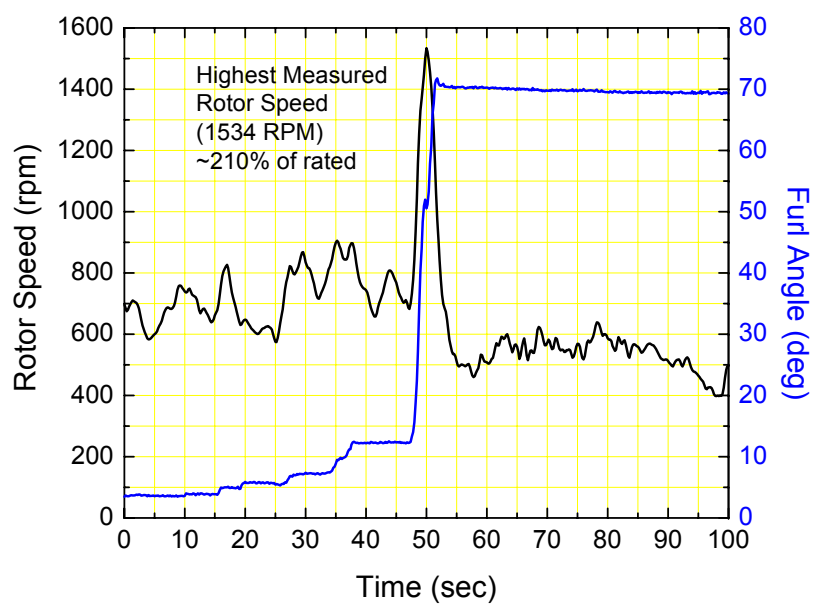

Figure 43. Measured rotor speed and furl angle during the gust which resulted in the highest measured rotor speed. 


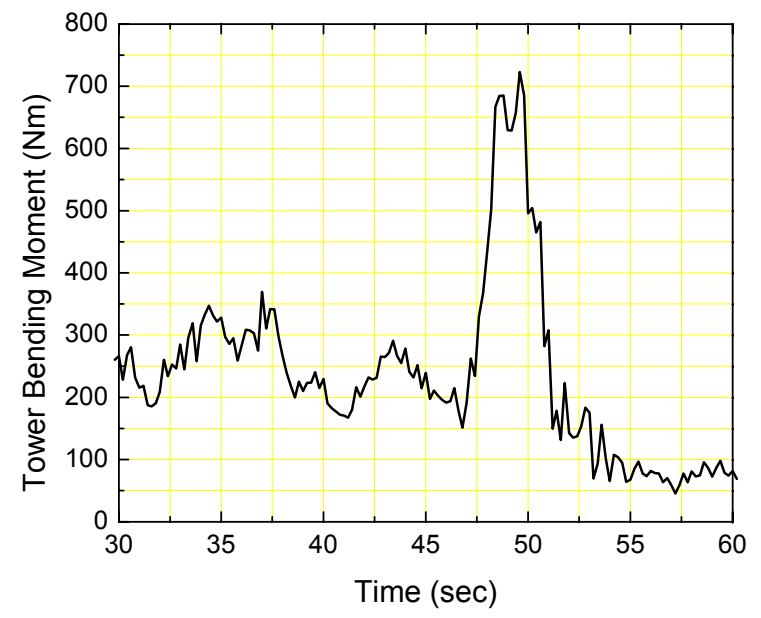

Figure 44. This event resulted in the highest measured tower bending moment $(723 \mathrm{Nm})$. 


\section{Load Extrapolation:}

Although there has been considerable research done on validation of load extrapolations for large wind turbines there has not been any research, to our knowledge, of load extrapolations on a small furling wind turbine. It appears that there are substantial differences in the nature of the turbine operation that must be understood before we can confidently use the extrapolations as a design tool. The large quantity of data that we recorded during our Whisper testing combined with the ADAMS model that we developed made this Field Verification Program an obvious choice for an initial investigation into using the load extrapolation routines for a small furling wind turbine. In this study $^{4}$ we used 1,573 hours of measured test data and 168 minutes of ADAMS simulation post-processed using the FITS [4] extrapolation routine. Next we compared the extrapolated maxima of the test data to the ADAMS simulations for both 1 year and 50 years. We also looked at how our measured maxima (captured during extreme wind events) compared to the extrapolated maxima. Figure 45 shows a comparison for four channels: blade flap bending moment, rotor speed, tower bending moment magnitude, and yaw rate.

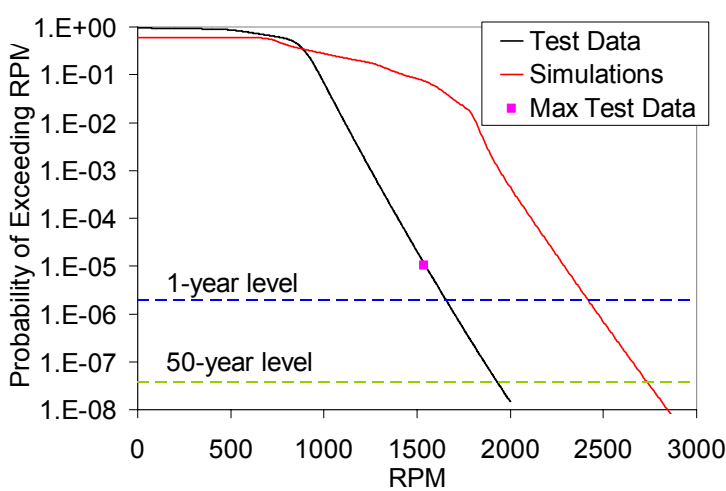

a

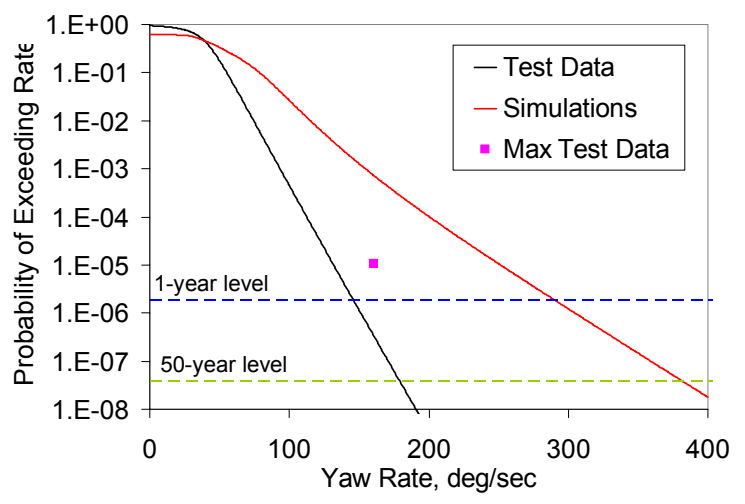

c

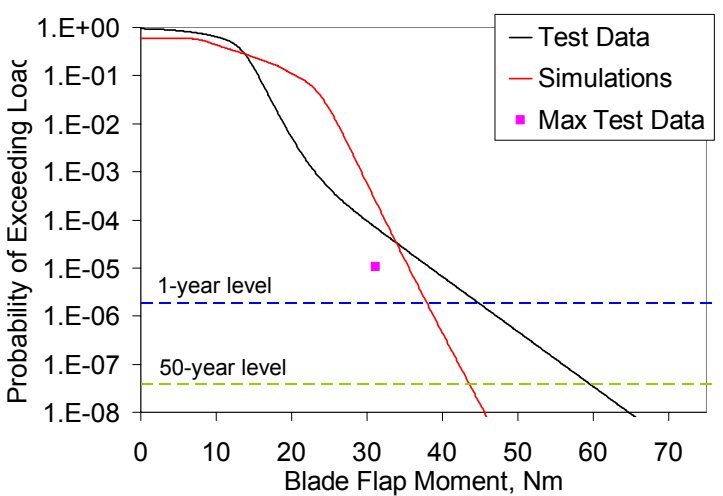

$\mathrm{b}$

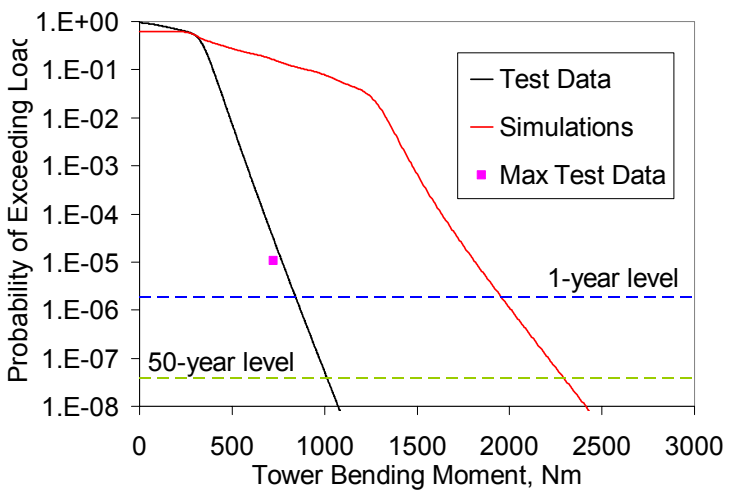

d

Figure 45. Probability of exceedence curves using Gumbel fits to all available data for a) rotor $\mathrm{RPM}^{5}$, b) blade flap bending moment, c) yaw rate and d) tower bending moment. Results from fitting Gumbel distributions to data in each $1 \mathrm{~m} / \mathrm{s}$ wind speed bin and integrating these over a Rayleigh distribution with a $10 \mathrm{~m} / \mathrm{s}$ mean wind speed.

Figure 45 also highlights that we extrapolated very different results when using the test data compared to the modeling simulations. To some extent this was a function of modeling very different winds (IECKAI turbulence)

\footnotetext{
${ }^{4}$ Greater detail of the study can be found in the AWEA Windpower 2003 paper titled: Estimates of Maximum Design Loads for a Whisper H40 Using Extrapolation Methods [3].

${ }^{5}$ It should be noted that the 50 year extrapolated value for the ADAMS simulation is $\sim 2700 \mathrm{rpm}$. This results in a tip speed of Mach 0.9. We do not account for any compressibility in the model aerodynamics and we don't expect the rotor speed would actually reach this high. We have measured over 1500rpm on the actual turbine which calculates to a Mach number of approximately 0.5 .
} 
than those seen during the test period at the Spanish Fork test site. When we filtered the data, using a smaller subset that was closer in turbulence intensity and wind speed range we generated the results seen in Figure 46. Although these results showed a reduction in the differences the results were still substantially different.

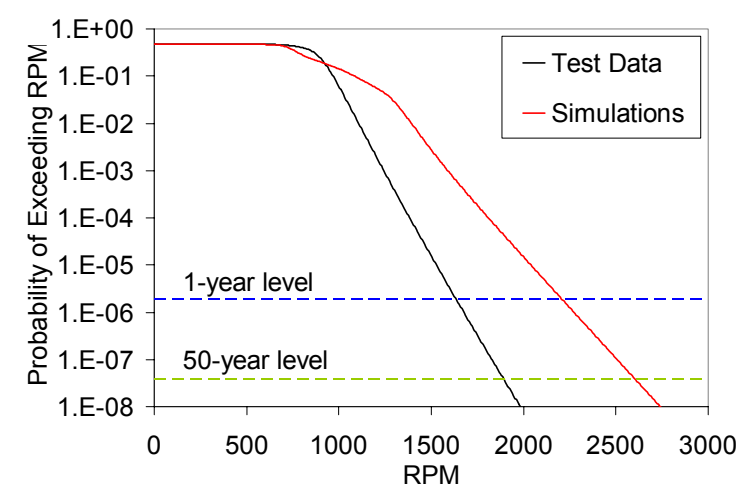

a

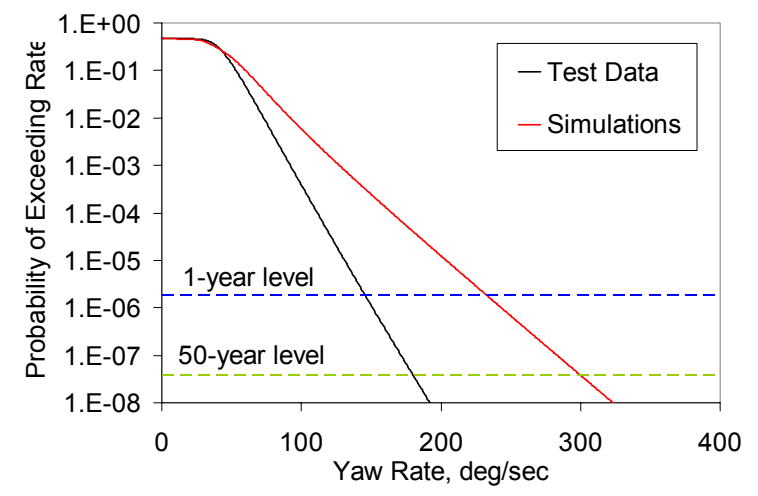

c

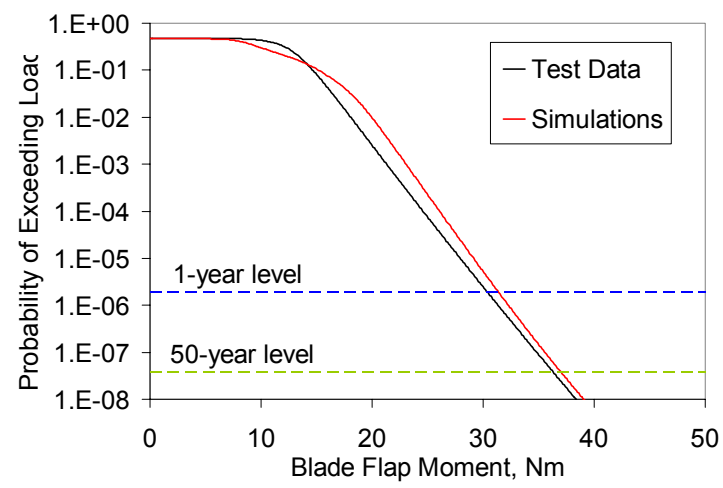

$\mathrm{b}$

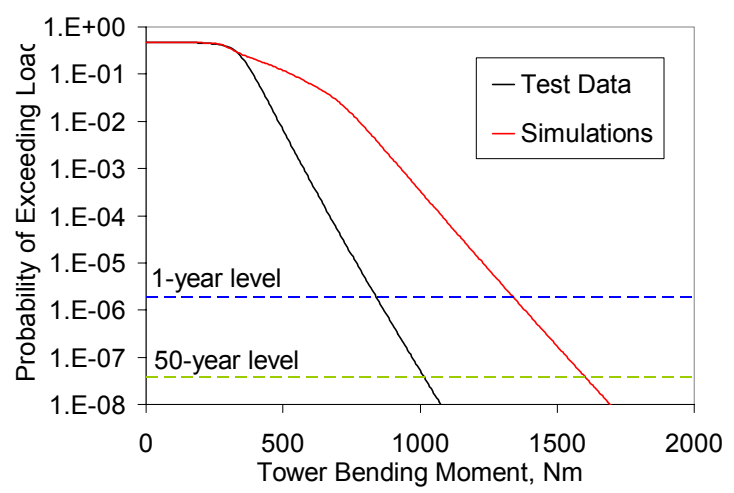

d

Figure 46. Probability of Exceedence curves using Gumbel fits to reduced data sets representing $7-14 \mathrm{~m} / \mathrm{s}$ for a) rotor RPM, b) blade flap bending moment, c) yaw rate and d) tower bending moment.

\section{Conclusions for Extrapolation Study:}

The extrapolated values from the ADAMS simulations initially ranged from $27 \%$ lower to $126 \%$ greater than the extrapolated values from test data (Figure 45). Although these predictions are poor there are numerous reasons why the predictions did not better match the data. These reasons are listed below (in the order, we believe, of most influential to least influential).

1. The ADAMS model tends to not fully furl in the high winds. This results in higher rotor speeds as well as higher loads. This is most obviously influencing the results in higher wind speeds but we feel it might be showing up in the lower wind speed data by over-predicting the rotor speed in gusts. When using simulations to extrapolate the maximum loads or turbine parameters, the model must accurately model the turbine operation and dynamics and must be able to predict the turbine behavior in gusty conditions as well as high winds. Inaccuracies in the modeling will be exaggerated when using the extrapolations.

2. There was very little simulation data (168 minutes of data which is only $0.032 \%$ of 1 year). Such a small sample of data further exaggerates any model inaccuracies and results in a very low confidence values when extrapolating out to 50 years. A larger data set would allow the statistical moments of the extreme data to converge. These statistical moments are crucial to the accuracy of the probability analysis conducted. 
3. The turbulence was very different between the test data and the model simulations. Although we made an attempt to compensate for this we did not go as far as correcting the extrapolations to account for the distribution of the turbulence intensity (TI). The current method permits integration over both wind speed and TI distributions, but doing so would have even further diluted the data sets by spreading them over far more bins.

4. The ADAMS simulations were based on an IEC $10 \mathrm{~m} / \mathrm{s}$ average site while the measured data was taken at the Spanish Fork test site which has a lower average wind speed and a bimodal wind distribution that is quite different from a Rayleigh distribution. Although the extrapolation routines adjust for the different wind distributions there will be errors introduced by this adjustment. With more complete data sets (representing wind speed and TI ranges), and integrating over both a wind speed and TI distribution, this would not be a factor. Having said that, however, it is obviously difficult - if not impossible - to collect data over a range of wind speeds and TI that do not occur often at your test site.

When we tried to compensate for three of the above-mentioned differences (all but number $2^{6}$ ), extrapolated model predictions were $2 \%$ to $67 \%$ greater than extrapolation predictions of test data, which is a significant improvement. Unfortunately due to time constraints we were unable to increase the quantity of simulation data ${ }^{7}$.

Extrapolation of test data to extreme values is also not as accurate as we would like. The highest observed yaw rate in our tests is greater than the value predicted by extrapolation for a comparable period while the opposite is true for the flap moment. This may be solely the result of a test period that was too short. However, we expect that our database is larger than may often be available during the certification of a turbine, so we are concerned that the current extrapolation methods may not be reliable for this purpose.

Finally, this study highlights a characteristic of small, passively furling wind turbines that makes it fundamentally difficult to predict maximum loads. The maximum rotor speed (a primary driver of loads) is an elusive number. In contrast, the maximum rotor speed of a large wind turbine is generally well defined and will typically be limited to less than $20 \%$ above the rated speed. With the Whisper H40, which is representative of many small furling wind turbines, we have measured a maximum rotor speed that is $210 \%{ }^{8}$ of rated during a gust that was less severe than the IEC 1-year Extreme Operating Gust (see the section titled Turbine Operation During Extreme Wind Events for details of this wind event and the turbine response). What makes this so troubling for prediction of maximum rotor speed, is that this gust does not appear very severe and would have provoked a benign response from the turbine if it occurred at a higher wind speed or when the turbine was partially furled, or possibly if the gust hit at a different wind direction. This is because the high rotor speed event is not only a function of the gust characteristics but also a function of the turbine operating state just prior to the gust. This may result in fewer occurrences of the high rotor speed event (since a combination of factors all need to be aligned) but it makes it very difficult to predict when it will happen and what other combinations might make it worse. For example, IEC 61400-1 requires that the IEC extreme gusts be simulated for winds between rated and cutout. With a small furling wind turbine neither of these cases will likely produce a maximum rotor speed event since the turbine will be partially or fully furled. Instead the worst case is likely to occur when the gust starts below the rated wind while the response may be benign for all gusts starting above rated wind. These elusive, yet potentially damaging events will not conform to the general distribution of the bulk of the data, and as a result will be essentially ignored in the current extrapolation process. It will be important that any extrapolation design tool not ignore these events since they hold valuable clues to the maximum loading of the wind turbine.

The above conclusions lead us to believe more research and understanding are needed before the extrapolation routines can confidently be used during the design or certification of a small passively furling wind turbine.

\footnotetext{
${ }^{6}$ Although we didn't address the problem of the ADAMS model not furling enough in higher winds directly, reducing the data sets to remove the high TI at high wind speeds resulted in filtering out much of the high wind, high furling, where the model is less accurate.

${ }^{7}$ Because of the high rotor speeds, and the need to keep many time steps per rotor revolution, these simulations run very slowly, i.e. 40 times real time. As a result, one 10-minute ADAMS simulation requires 400-minutes (6.7 hours) of computer time.

${ }^{8}$ This was measured with the turbine fully loaded and without any faults. Gusts combined with faults such as a loss of load will obviously result in higher rotor speeds.
} 


\section{Summary:}

We feel this program was highly successful in demonstrating the reliability, performance, and energy production of the Southwest Windpower Whisper H40 wind turbine. In addition we feel that the project has shed valuable light on the mechanics and nature of furling, which is useful information for turbine designers. These goals were accomplished with long-term, continuous (10-minute) data collection combined with short-term (high sample rate) data and ADAMS computer modeling. The long-term data collection spanned a period of over three and a half years with a substantial portion of that time monitored at the higher sample rate.

The Whisper H40 turbine and inverter operated with an overall availability of 98\% during this 3.5 year test program. The complete system availability was $74 \%$, with most of the downtime associated with instrumentation and data logging installation and maintenance. The system delivered $3425 \mathrm{kWh}$ to the grid. The rectifier, inverter and battery bank had an average efficiency of $77 \%$. The inverter and disconnect accounted for $54 \%$ of the total system cost.

Validation of the ADAMS computer modeling showed that the model accurately predicted the turbine behavior in the low and moderate wind speeds. The ADAMS model tended to under-predict furling angle in higher winds, leading to less accurate prediction of rotor speed and loads.

Three papers were submitted, accepted, and presented at AWEA's annual conferences for the years 2001, 2002, and 2003. These papers highlighted the project, showed turbine operation during extreme wind events, and investigated using extrapolation routines for determining design loads for a small furling wind turbine.

\section{Acknowledgements:}

- U.S. Department of Energy \& NREL/NWTC for providing support of this research.

- Utah Municipal Power Agency (UMPA) for providing the Spanish Fork, UT test facility.

- City of Spanish Fork, UT for providing use of the test site.

\section{References:}

[1] Davis, D. and A. C. Hansen (2001). Performance, Reliability and ADAMS model Predictions of a Small Furling Wind Turbine (Southwest Windpower Whisper H40). Windpower '01, Washington DC, American Wind Energy Association.

[2] Davis, D. and A. C. Hansen (2002). Operation and Load Measurements During Extreme Wind Events For a Southwest Windpower Whisper H40. Windpower '02, Portland, OR, American Wind Energy Association.

[3] Davis, D., A. C. Hansen and D. J. Laino (2003). Estimates of Maximum Design Loads for a Whisper H40 Using Extrapolation Methods. Windpower '03, Austin, TX, American Wind Energy Association.

[4] Manuel, L., Kasef, T., Winterstein, S. R., Moment-based probability modeling and extreme response estimation - The FITS routine Version 1.2, SAND99-2985, Sandia National Laboratories, Albuquerque, NM, Nov. ,1999.

[5] Anderson, R., Burks, J., Turner, T., Schrieber, O., Wilson, D. Utah Wind Survey Report. State of Utah Natural Resources Division of Energy. 